\title{
Diagnostics, rehabilitation and models of Parkinson's disease
}

\author{
Juliana Dushanova
}

Institute of Neurobiology, Bulgarian Academy of Sciences, Sofia, Bulgaria; juliana@bio.bas.bg

Received 8 September 2012; revised 11 October 2012; accepted 19 October 2012

\section{ABSTRACT}

Diagnostics and rehabilitation of Parkinson's disease (PD) presents the current information pertaining to etiology, early biomarkers for diagnostics, novel methods to evaluate symptoms, multidisciplinary rehabilitation, new applications of brain imaging and invasive methods to the study of PD. Researchers have only recently begun to focus on the non-motor symptoms of PD, which are poorly recognized and inadequately treated by clinicians. The nonmotor symptoms of PD have a significant impact on patient quality of life and mortality, and include cognitive impairments, autonomic, gastrointestinal, and sensory symptoms. In-depth discussion of the use of imaging tools to study disease mechanisms is also provided, with emphasis on the abnormal network organization in parkinsonism. Deep brain stimulation management is a paradigm-shifting therapy for PD, essential tremor and dystonia. In the recent years, new approaches of early diagnostics, training programmes and treatments have vastly improved the lives of people with PD, substantially reducing symptoms and significantly delaying disability. PD results primarily from the death of dopaminergic neurons in the substantia nigra. Current PD medications treat symptoms; none halt or retard dopaminergic neuron degeneration. The main obstacle to developing neuroprotective therapies is a limited understanding of the key molecular mechanisms that provoke neurodegeneration. The discovery of PD genes has led to the hypothesis that misfolding of proteins and dysfunction of the ubiquitin-proteasome pathway are pivotal to PD pathogenesis. Previously implicated culprits in PD neurodegeneration, mitochondrial dysfunction and oxidative stress, may also act in part by causing the accumulation of misfolded proteins, in addition to producing other deleterious events in dopami- nergic neurons. Neurotoxin-based models have been important in elucidating the molecular cascade of cell death in dopaminergic neurons. PD models based on the manipulation of PD genes should prove valuable in elucidating important aspects of the disease, such as selective vulnerability of substantia nigra dopaminergic neurons to the degenerative process.

Keywords: Parkinson's Disease; Diagnostics; Rehabilitation; Models

\section{INTRODUCTION}

We have based this review on the philosophy that one has control over how PD affects the life of a person who will fight believing that through support and maximizing personal strengths, life will continue to have meaning and richness. The fighting begins in partnership with the physicians with the understanding as much as possible about PD, medications, and non-drug therapies so that a person can be participate in the health-care decisions that uniquely affect the self. A person who has PD does not mean he will experience all possible symptoms. We have designed this review in modules, each dealing with a different aspect of PD and be selective in what topics is pertinent to symptoms and health-care decisions.

The review first gives an introduction to "prediagnostic" phase of PD or early markers for the diagnosis of PD as non-motor symptoms such as mood disorders, olfactory, vegetative, sensory or neuropsychological signs may be noticed by the patients or physicians in advance of motor signs reflecting the dysfunction of dopaminergic or non-dopaminergic neurons. It concentrates on the novel methods to evaluate symptoms in PD and focuses on multidisciplinary cognitive rehabilitation in PD. The review deals with practical issues that are critical for the invasive methods examined in patients with PD and describe all aspects of both clinical as pathophysiological and therapeutic concerning PD, as well as an update on the innovative aspects of the disease primarily focused on identifying new pathophysiological 
factors and new outlook therapeutics. The review spans the experience of scientists from different fields and to be useful also for clinicians who take health care for people with PD and their families. It should appeal to a multidisciplinary audience and help people cope with medical, emotional, and practical challenges.

\section{DIAGNOSTICS OF PARKINSON'S DISEASE}

$\mathrm{PD}$ is a progressive neurologic disorder affecting 1 in 100 people over the age of 50. Typically the diagnosis is made in the sixth or seventh decades of life, with approximately $7 \%$ of people diagnosed before the age of 40. It has been well documented that PD is also characterized by a long preclinical phase from the onset of dopamine neuron loss to the onset of motor symptoms. In the recent years light was thrown on non-motor symptoms such as autonomic dysfunction, pain and cognitive decline. Approximately $10 \%$ of subjects older than 60 years are in the prediagnostic phase of PD and exhibit the pathological hallmarks of PD, like Lewy bodies and neuronal loss at the substantia nigra (SN), without showing the motor signs during life time that allow the diagnosis of PD. There is enough evidence to show that cognitive deficits affect quality of life. Thus, there is an urgent need to develop imaging modality to screen individuals who may be in the preclinical phase of PD for earlier diagnosis and treatment to slowdown or stop progression of the disease. Parkinsonian symptoms such as tremor, rigidity, akinesia, postural instability and facial expression are perceived subjectively, and therefore understanding the degree of the symptoms varies depending on the neurologist.

The neuroimaging examination could help to evaluate PD subjects in the preclinical stage. Conventional MR imaging, as well as different advanced MRI techniques, including magnetic resonance spectroscopy, diffusionweighted and diffusion tensor imaging are helpful to distinguish PD from atypical or secondary PD. The secondary symptoms of PD may affect some but not all people. These include changes in speech and swallowing, bowel and bladder function, fatigue, mood and memory, sexual function and sleep. Speech of patients with PD is characterized as hypokinetic dysarthria, manifesting itself by low volume, diminished voice quality, flattened prosody and deteriorated articulation. Patients with mild cognitive deficits have a higher risk for developing dementia. The interventions in early stages of cognitive decline might slow down the progress of cognitive deficits or even prevent the development of dementia. Brain event-related oscillations are one of the promising candidates explaining the neural mechanisms at central nervous system in Parkinson's patients and give a useful tool for detecting subtle abnormalities of the cognitive processes. The sustained yield of a multidisciplinary training programme on cognitive function of PD patients with mild cognitive deficits is to support patients to manage their daily life better and to become more selfconfident. When symptoms first appear, they are very mild and sometimes intermittent. As the disease progresses the symptoms become more pronounced and more persistent. The primary symptoms of PD are tremor, rigidity, bradykinesia (slowness), and impaired balance but not all symptoms need to be present to make the diagnosis. Tremor is most prominent when a person is sitting quietly and improves or disappears when the person is using their arms or legs. That is why Parkinson tremor is described as a resting tremor. Rigidity is stiffness of muscles. As the disease progresses, the stiffness is perceived as a cramp or tired, aching muscles. This rigidity is associated with the flexion posture characteristic of PD. Rigidity responds well to a combination of medications and a vigorous stretching program. Bradykinesia means slowness of movement. Fine movements, such as writing, becomes more clumsy. Another manifestation of bradykinesia is loss of associated movements. These are movements outside of one's awareness: blinking the eyes, facial expression, swallowing, swinging the arms, and changes of posture. The overall appearance is one of unusual stillness when a person is sitting quietly. Bradykinesia also affects voluntary movement. Medication can be very helpful in improving bradykinesia. Impaired balance occurs because of a change in postural reflexes. These are the reflexes that facilitate rapid changes in the center of balance when walking or standing. A person will notice a feeling of unsteadiness and in later stages of disease may have a tendency to list to one side or the other and may even fall backwards or forwards. Medication is less helpful for balance problems than for rigidity or bradykinesia. Physical therapy can be very helpful in teaching safety maneuvers, balance exercises, and providing consultation regarding ambulation aids.

Parkinsonism is the loss of dopamine-producing cells in an area of the brain stem called the substantia nigra. These nerve cells project fibers to areas deep in the brain called the basal ganglia. The function of the neurochemical, dopamine, is to allow nerve impulses to run smoothly along these fibers and transmit messages to muscles of the body producing normal movement. When the supply of dopamine is decreased by approximately $80 \%$ the symptoms of PD emerge. Over time the loss of dopamine-producing cells continues and symptoms become more severe. The current debate is whether nerve cell loss is something that has a genetic link occurring slowly over time or happens suddenly after being exposed to a toxic substance. It may be a combination of these two theories. It has been suggested that some people are 
genetically predisposed to developing PD and therefore more susceptible to the potential damage of a toxic exposure.

PD progresses slowly. The rate of progression varies, making it difficult to give patients and families definitive information that can provide them the comfort of knowing what to expect and how to prepare for their future. The studies that have attempted to describe the prognosis of PD have been hard to interpret because drug therapy treats the symptoms. Drug treatment, specifically levodopa therapy, slows the onset of disability. Disability will eventually occur and increase while on therapy but this is usually because of the emergence of new symptoms that do not respond to levodopa.

\section{REHABILITATION OF PARKINSON'S DISEASE}

People should consider how Parkinson's symptoms might alter performance and think of ways to modify their work environment or their type of work. It is also important to remember that current researches offer tangible possibilities that could change the course of PD. Gene therapy, surgical therapies, rehabilitation, and drugs that delay progression hold great hope for changing the disability of PD. The training tasks are allocated to different categories: concentration, strategy, improvement of orientation, planning, use of mnemonic devices. Impulse control, decision processes, listening training and memory, and also a special programme with the aim to learn motor sequences, dual tasking, orientation in a room. The motor training helped patients to deal with their cognitive problems; many patients are afraid of the cognitive deficits and rather try to hide than to approach the problems. Physical activity improves cognitive functions especially executive functions which are important for daily living. Sport is as well an activity to get the partners involved. Social aspects are important for the continuation of the training and as well important to prevent depression. Depression and social isolation are closely associated with cognitive decline. The new ICT systems are able to evaluate the variation of symptoms along whole the time the patient is wearing the sensors and provide useful information to physicians in order to allow them make decisions more accurate, more efficient and quicker. Long-term multimodal exercise programs can improve both motor and cognitive impairments in people with $\mathrm{PD}$, which could have a broader impact on quality of life than specific exercise interventions.

Predating the diagnosis of PD and identifying subjects at risk will be one important goal for future research aimed to postpone the onset of the disease by neuroprotective therapy.

\section{BIOMARKERS FOR PRECLINICAL DIAGNOSIS OF PD}

Several procedures $[1,2]$ have been proposed to identify subjects in early stages of PD as the saccadic eye movements to investigate and quantify motor impairments in PD, and a new vision-based nonintrusive eye tracker as a possible tool for supporting the diagnosis of PD in association with levodopa test. A more complex relationship between brain iron changes and disease state in PD has revealed different metabolic patterns and a reduced capacity of the macromolecules in brain tissue to exchange magnetization with the surrounding water molecules was found in the substantia nigra pars compacta, substantia nigra pars reticulate, red nucleus in PD $[3,4]$. Diffusion Weighted Imaging and a statistical parametric mapping localized significant increases of diffusivity in the region of both olfactory tracts in patients with PD compared to healthy controls [5]. This observation is in line with the well-established clinical finding of hyposmia in early PD [6]. Olfactory dysfunction may be considered a reliable marker of PD [7]. Objective olfaction tests are olfactory-evoked potentials or functional magnetic resonance imaging (fMRI). These techniques have been used to assess the severity of olfactory dysfunction and its correlation with cerebral changes in studies carried out in early PD patients $[7,8]$. Effective differential diagnosis of PD needs in informative indexes that objectively reflect the functional state of the extrapyramidal system [9]. Such informative diagnostic indexes in PD are surface electromyograms (EMGs) and brain evoked potentials $[9,10]$. The fractal analysis of EMG is sensitive to neuromuscular status $[11,12]$. The contingent negative variation is a sensitive indicator for the objective evaluation of the severity of PD and to quantify the efficacy of the therapy [13]. Deviations of the auditorily and visual elicited brain oscillatory responses at specific frequencies in association with sensorimotor and cognitive processes for the Parkinson's patients compared to healthy controls are a evidence for disturbances in the temporal and regional integration of these frequency components and the relationships between cortical and the basal ganglia circuits in parkinsonism [14-16]. [17-19] has been trying to introduce in developing of MRI-based imaging biomarkers for early detection of PD. The imaging method as pharmacological MRI [20-23] can detect functional deficiency of the nigrostriatal system. The objectives of the [24-32] are the use of neuroimaging such as magnetic resonance spectroscopy (MRS), single-photon emission computed tomography (SPECT), positron emission tomography (PET), diffusion tensor imaging (DTI), and functional MRI (fMRI) in manganese-induced Parkinsonism and the assessment of the neural correlates of manganeseinduced memory impairment in response to a subclinical 
dysfunction of working memory network in welders with chronic manganese exposure. [33-38] give a systematic and exhaustive depiction of element levels $(\mathrm{Cu}, \mathrm{Fe}, \mathrm{Zn}$, $\mathrm{Cr}, \mathrm{Be}, \mathrm{Cd}, \mathrm{Cr}, \mathrm{Hg}, \mathrm{Se}, \mathrm{Si}, \mathrm{V}, \mathrm{Mn}, \mathrm{Cu}, \mathrm{Co}, \mathrm{Pb}, \mathrm{Ni}$ ) in the cerebrospinal fluid of PD patients and paired controls and verify the influence on the results of number, age, gender of the subjects and health conditions with regard to clinical variables as duration and severity of the disease and pharmacological therapies. [39-42] consider the underlying mechanisms of the subtle language impairments in non-demented PD patients. Recently functional imaging in PD patients has begun to add information to the underlying nature of the language impairments in PD, both comprehension and production deficits at the word, sentence and discourse level.

\section{NOVEL METHODS TO EVALUATE SYMPTOMS IN PD}

The novel methods for evaluation the symptoms in PD deal with the sensing systems identifying rigidity or spasticity and the nature of abnormal finger tapping in PD and show Parkinsonian symptoms as a system error in software of repetitive movement [43-45]. Among Parkinsonian signs, speech impairment represent an important disabling symptom able to lead towards a significant reduction of oral communication. The principal methods for PD speech evaluation are reviewed in [46$48]$ prior to the presentation of the use and relevance of aerodynamic parameters for Parkinsonin dysarthria evaluation. The analytical method based on power-law temporal auto-correlation of physical activity collected by an actigraph device enables evaluation of the severity of Parkinsonism with sufficient sensitivity and reliability, and is useful for the evaluation of efficacy of therapy for Parkinsonism [49-51]. Postural control while sitting with or without arm raising and its association with risk of falls in patients with PD was discussed in [52,53].

\section{MULTIDISCIPLINARY COGNITIVE REHABILITATION IN PD}

A study on cognitive training in $\mathrm{PD}$ and compared different types of cognitive training is discussed in [5457]. The studies assess the effect and sustained yield of a multidisciplinary training programme on cognitive function of PD patients with mild cognitive deficits. [58-62] propose modules known as systems for support the decision-making which allow doctors and clinicians be more agile in the decision-making process improving the time that they need and the quality of information that they have. The researches explore the impact of impaired decision making ability upon the driving performance of people with PD [63-66]. The effectiveness of a long-term multimodal exercise program based on the improvement of the functional capacity components in improving clinical parameters, functional mobility and cognitive function in people with PD was demonstrated in [67-71]. The research areas with respect to the development, implementation and evaluation of telehealth applications for speech therapy in dysarthric speakers with PD are addressed in [72]. The relevant and the long-term efficiency of a physiotherapy program in PD are demonstrated in [73-75]. Normotensive therapy is a specific rehabilitation to control of postures and it uses of a supporting elastic expander while exercising and a traumatic normalization of the tissues, and allow mobility to be restored without any pain [76-79]. A sit-to-stand assistance system is developed, and used to assist individuals with PD who could or could not stand up without help [80].

\section{INVASIVE METHODS EXAMINED IN PD PATIENTS}

A review of the use of deep brain stimulation (DPS) electrodes for externally controlled recording or stimulation at the level of basal ganglia nuclei discussed the physiological observations underlying the engagement of structures affected by the electrical field around the electrode in motor and sensory functions [81-84]. Based on the information from the fused images of preoperative MRI-postoperative computer tomography, it was emphasized that the documentation of the electrode position by using mutual information technique after unilateral or bilateral STN stimulation provides useful information for the prediction of the surgical outcome [85-90]. Fusionimage-based programming and reprogramming of the stimulator parameters using the visual information of the location of the electrode contacts propose to find the best sites and the best stimulation parameters for the advanced PD patients treated with deep brain stimulation of subthalamic nucleus (STN-DBS). The electrical motor cortex stimulation can improve axial symptom of $\mathrm{PD}$, which is difficult even with STN-DBS, and is less surgical invasiveness than deep brain stimulation can make the surgery safer for the patients with advanced age or sever brain atrophy [91,92]. Other contribution in the PD research deals with the rational arthroplasty surgery and multidisciplinary approaches for the patients with PD $[93,94]$.

\section{MODELS AND TREATMENTS OF PD}

$\mathrm{PD}$ is characterized by a loss of dopaminergic neurons from the substantia nigra pars compacta $(\mathrm{SNc})$. The $\mathrm{SNc}$ is part of the substantia nigra, which belongs to the group of nuclei in the midbrain, called the basal ganglia. The function of the basal ganglia requires signaling of both excitatory and inhibitory neurotransmitters to balance the 
two main signaling pathways, the direct and indirect pathways. These pathways remain balanced by the nigrostriatal pathway or the dopaminergic projections from the $\mathrm{SNc}$ to the striatum (caudate nucleus and putamen) with a basal level of striatal dopaminergic DA integral for proper function of the basal ganglia. A basal ganglia structure performing neurotransmitter-mediated operations through somatotopically organized projections to GABAergic medium spiny projection neurons (MSNs). These striatal cells are innervated by excitatory glutamatergic fibers from cortex and thalamus, and modulatory dopaminergic fibers from the midbrain and transmit neural information to the basal ganglia output structures. Neural transmission at the level of MSNs has been associated with the regulation of voluntary movement and cognitive functions. Knowledge of the new transmitter mechanisms by which such interactions take place can provide new insight into the basal ganglia physiopathology and new clues for therapy of severe motor disorders such as PD. Thus in PD, the loss of dopamine neurons causes the subsequent loss of striatal dopamine, and the presentation of motor symptoms such as bradykinesia, akinesia, rigidity and postural instability. The movement disorders are often associated with abnormalities in electrical activity within the substantia nigra pars reticulata. Parkinson's is a complex disorder involving alterations in brain chemistry, morphology and activity, and an enhanced understanding of the interdependence of these processes will increase our understanding of this devastating disease.

Accordingly, current treatment of PD involves increasing striatal dopamine content, by either direct replacement or reduction of its breakdown. Unfortunately, these treatments only provide symptomatic relief and the efficacy is somewhat limited. For example, the current "gold-standard" treatment for PD, L-DOPA, the precursor to dopamine, only alleviates symptoms for 5 to 10 years before debilitating side effects such as dyskinesia appears. The underlying pathogenesis of degenerating DA neurons still remains unknown. Importantly for potential PD therapeutics, the loss of neurons occurs slowly over many years suggesting that there is a window of opportunity within which a neuroprotective therapy could be administered to slow or halt the progression of the disease. However, to date, no neuroprotective therapies are currently in clinical use. As such, new avenues of research into the pathogenesis of PD and the discovery of possible neuroprotective agents are critical.

Evidence from both clinical and experimental models of PD have elucidated a number of mechanisms that are attributed to the continuing loss of DA neurons such as oxidative stress, mitochondrial dysfunction, and glutamate excitotoxicity. More recently, inflammatory processes, particularly the chronic activation of microglia, and blood brain barrier (BBB) dysfunction have gained much attention for their potential role in the pathogenesis of PD. There is evidence that oxidative stress participates in the neurodegeneration. Neutrophils express a primary alteration of nitric oxide release in PD patients, where reactive oxygen species and oxidative stress parameters are more probably related to the evolution of PD. Peripheral markers of oxidative stress in red blood cells of neurological patients could be a reflection of the brain condition and suggests that oxygen free radicals are partially responsible of the damage observed in PD living patient. Other reports suggest that mitochondrial dysfunction and impairment of the respiratory complexes are associated with the neuronal loss. Substantial evidence suggests diet, in particular iron intake, and environmental risk factors such as pesticides and heavy metals as causative of PD. However, how genetic and environmental factors are related to the nutritional status of PD patients is still unknown. Moreover, how the nutritional status of PD patients might contribute to the development of the disorder is not yet established. Drosophila melanogaster is used as a valid model in PD research to investigate the effect of paraquat and iron alone or in combination and polyphenols upon two different glucose feeding regimens on the life span and locomotor activity of the fly. The concept of oxidative stress is defined as an imbalance with increased oxidants or decreased antioxidants. The situations of oxidative stress, evaluated by the peripheral markers of oxidative stress in the blood of neurological patients, seem to afford a reflection of the brain condition. Brain oxidative stress, with oxygen free radicals being responsible for brain damage, provides signals to peripheral blood, at least, through the diffusible products of lipid peroxidation.

The neuropeptide, substance P (SP) is widely distributed throughout both the central and peripheral nervous systems. Generally in PD, it is considered, that SP expression within the $\mathrm{SN}$ is decreased, with such loss of SP also being attributed to symptom presentation. However, most studies have used post-mortem PD cases or experimental models of PD with maximal dopaminergic degeneration, which both replicate the late stages of the disease. In these final stages, the reduction in striatal DA input has resulted in a loss of the SP/DA positive feedback mechanism and consequently the reduction in nigral SP. Indeed, it has been shown that SP content within the $\mathrm{SN}$ is not reduced until greater than $90 \%$ of striatal DA has been depleted. SP content within the SN has yet to be directly measured in early clinical PD.

A prevalent etiologic hypothesis is that PD may result from a complex interaction between environmental toxic factors, genetic susceptibility traits and aging. In the initial stages of disease, levodopa therapy is the most effective for improving motor symptoms PD. However, 
long-term treatment with levodopa is accompanied by fluctuations in motor performance, dyskinesias, and neuropsychiatric complications. A disease-modifying therapy is the most important unmet medical need in the treatment of PD. New information has become available on the mechanism responsible for levodopa-induced motor complications and the potential value of therapies that provide more continuous dopaminergic stimulation.

Little mathematical modeling has been offered for PD. Drosophila research into PD has focused on the transgenic expression of human alpha-synuclein in fly neurons and on the comprehensive investigation of two genes responsible for recessive PD, parkin and PINK1. Finally, the advantages of Drosophila as a model will continue to advance our understanding of the mechanisms that contribute to PD, and to aid in the design of therapeutic treatments with implications for other degenerative diseases and ageing processes.

Many drugs used to treat PD are effective in many patients, but do not retard the degeneration of the brain regions affected by the disease. Their effectiveness diminishes over time and their adverse effects become increasingly more troublesome. Therefore, new therapeutic approaches are required. Clinical and biochemical evidences suggest that PD involves multifactorial oxidative neurodegeneration and that levodopa therapy aggravates the oxidative burden. It is demonstrated that PD is primarily an oxidative disease and can be induced by endogenous and exogenous environmental oxidant stressors. Several lines of evidences indicate also that mitochondrial dysfunctions play an important role in the pathophysiology of PD contributing to the development and progression of the disease. Recent studies show that two of the four major genes (DJI and PINK1) involved in familial PD are of mitochondrial origin. Mutations of these genes increase cell susceptibility to stressful conditions inducing mitochondrial dysfunction and apoptosis. Mitochondrial antioxidants/nutrients can improve mitochondrial functions and protect mitochondria against oxidative damage. It has been shown that they have neuroprotective effects against PD in cellular and animal models as well as in clinical trials. The mitochondrial antioxidant/nutrient acetyl-L-carnitine (ALC), with its well known antioxidant energizing protective activities and with its trophic effects, at optimal doses can be an effective and safe prevention strategy for PD.

Idiopathic PD is thought to represent a complex interaction between the inherent vulnerability of the nigrostriatal dopaminergic system, a possible genetic predisposition, and exposure to environmental toxins including inflammatory triggers. Accumulating evidence now suggests that chronic neuroinflammation is consistently associated with the pathophysiology of PD. Activation of microglia, the resident immune cells of the brain has been reported after post mortem analysis of the substantia nigra pars compacta in brains from PD patients. Equally, increased levels of pro-inflammatory mediators, reactive oxygen species and eicosanoids have been repeatedly reported in the brain of PD patients. It is hypothesized that chronically activated microglia secrete high levels of pro-inflammatory mediators which damage neurons and further activate microglia, resulting in a feed forward cycle promoting further inflammation and neurodegeneration. Moreover, nigrostriatal dopaminergic neurons are more vulnerable to pro-inflammatory and oxidative mediators than other cell types because of their low intracellular glutathione concentration. Systemic inflammation has also been suggested to contribute to neuroinflammation and consequently neurodegeneration in PD, as lymphocyte infiltration has been observed in brains of PD patients. Epidemiological reports of reduced susceptibility to PD, among chronic users of antiinflammatory drugs have also provided evidence of a link between inflammation and PD. Intriguing new evidence now suggests that exposure to systemic inflammation pre-birth or in early life, and the consequent induction of neuroinflammation throughout the lifespan of an individual, contributes to the evolution of neurodegenerative disorders like PD. Sustained microglial activation, elevated pro-inflammatory mediators and lymphocyte infiltration have also all been observed in animal models of PD, substantiating the current belief of a fundamental role of inflammation in neurodegeneration.

The molecular pathways underlying the pathogenesis of the disease remain poorly understood. Interestingly, recent studies suggest that cyclin-dependent kinase 5 (Cdk5), a serine/threonine kinase that is predominantly active in neurons, plays a pivotal role in neuronal loss in models of PD. Cdk5 is typically activated by its activator p35 and p39, and is implicated in a plethora of neuronal functions including neuronal migration, neuronal survival and differentiation, and the regulation of synaptic functions. Cleavage of p35 into a p25 fragment during pathological condition results in prolonged and aberrant activation of Cdk5. Importantly, p25-mediated activation of Cdk5 has been associated with neuronal loss in MPTP-toxicity model of PD. MPTP-induced neuronal loss is markedly attenuated in p35-deficient mice. Subsequent studies have identified several substrates of $\mathrm{Cdk} 5$ that may underlie the critical role of $\mathrm{Cdk} 5$ in MPTP toxicity. For example, phosphorylation of survival factor MEF2 by Cdk5 was found to inactivate MEF2, in addition to promoting its degradation. In addition, Cdk5mediated phosphorylation of antioxidant enzyme Prx2 and an enzyme crucial for repair of DNA damage, apurinic/apyrimidinic endonuclease 1 (Ape1), have both been demonstrated to contribute to MPTP-induced neu- 
ronal loss.

The tridecapeptide neurotensin (NT), widely distributed both in the peripheral and in the central nervous system (CNS) of mammals, including humans, acts as a primary neurotransmitter or neuromodulator of classical neurotransmitters. NT is synthesized in neurons and released by sodium and calcium-dependent mechanisms and three major subtypes of NT receptors named NTS1, NTS2 and NTS3, are largely distributed in different discrete areas in the brain as well as in the periphery. NT has been shown to be closely associated with the dopaminergic system, implicated in the PD. The functional evidence, that NT modulates dopaminergic transmission, especially the nigrostriatal and mesocorticolimbic DA pathways, have suggested that the NT regulation of this system may have important implications for the pathophysiology and development of treatments of these disorders. The NT receptor antagonists could be used as a treatment strategy for PD. In addition, NT plays a crucial role also in the regulation of the glutamatergic transmission. Evidence has accumulated that glutamate, is an important mediator of neuronal injury. In view of the enhancing effects of NT on glutamate transmission, this peptide may play a relevant role in reinforcing the glutamate-mediated excitotoxicity as demonstrated in primary cultures of mesencephalic DA and cortical neurons.

The majority of cases of PD are idiopathic, and with the exception of isolated toxin induced cases such as MPTP (1-methyl-4-phenyl-1,2,3,6-tetrahydropyridine), underlying environmental causes remain to be discovered. However, approximately $15 \%$ of individuals with PD have a first-degree relative who also has the disease, and $5 \%-10 \%$ of PD sufferers are known to have monogenic forms of the disease. Furthermore, a number of the genes identified in familial PD have been implicated in, and as risk factors for sporadic disease. Currently, without a defined aetiology of the sporadic disease, studying the molecular mechanisms by which the genetic and toxic forms progress in animal models offers a valuable resource to gain insight into the sporadic disease.

The loss of nigrostriatal dopaminergic neurons (predominately in the substantia nigra pars compacta) as well as noradrenergic neurons of the locus coeruleus with the concomitant of intracytoplasmic protein aggregates termed Lewy bodies in surviving neurons, is considered the defining pathological feature of PD [95,96]. Based on Lewy body deposition, it has been suggested PD first affects the olfactory bulbs and caudal brainstem nuclei, and then progresses rostrally to the substantia nigra, which does not become involved until disease is moderately advanced. However, dopamine supplementation to reverse depleted dopamine output from the substantia nigra pars compacta is the mainstay pharmacological intervention for PD. Drugs such as levodopa alleviate the symptomatic motor decline of PD only; they do not address the nonmotor features related to degeneration of nondopaminergic systems. As the disease progresses dopamine supplementation becomes less efficient and dyskinesia and behavioral abnormalities may develop. Interestingly, a recent study has reported that the neural loss in PD in Locus coreleus is greater than that in substantia nigra. The influence of noradrenergic neurotransmission on dopamine-mediated behaviour has been the focus of several studies over the last four decades, and has confirmed the importance of the relationship between dopaminergic and noradrenergic pathways in the control of locomotor activity. It has been suggested that progressive neurodegeneration of the main noradrenergic nucleus - the locus coeruleus - might influence not only the progression of PD but also the response to dopaminergic replacement. Furthermore, additional evidences support the notion that noradrenaline deficit might be relevant for the pathogenesis of long-term complications of L-DOPA treatment such as the wearing-off phenomenon and dyskinesias.

However, in spite of the bulk of data on the influence of an alteration of noradrenergic transmission on locomotor behaviour, much of these data is conflicting and not conclusive. Therefore, definitive conclusions, as to the specific role of the noradrenergic system in the generation of symptoms of PD and L-DOPA-induced dyskinesia LID, cannot yet be drawn. Based on a number of behavioral studies, demonstrating the alleviation of dyskinesia by $\alpha_{2}$ adrenergic receptor antagonists, in addition to other biochemical studies, some studies hypothesized that the noradrenergic system also plays a role in the neural mechanisms underlying PD and L-DOPAinduced dyskinesia [97].

New intervention strategies $[98,99]$ focused on modifying the disease process, as opposed to the current symptom-alleviating management of the disease, are considered necessary for PD. Since direct regeneration of brain tissues is difficult to achieve, an alternate supply of neural cells is required in order to attain any therapeutic goal. Recent progress in stem cell biology has led to new approaches to the generation of neurons.

Animal models provide a platform to delineate the pathogenic mechanisms of $\mathrm{PD}$, and studies involving primates, rodent (rat and mouse), zebrafish, nematodes and fruit fly have been instrumental to further understanding of PD. Models of neurotoxins such as MPTP can mimic the loss of dopaminergic neurons and are useful as models of characteristic motor symptoms of PD however they lack of age-dependent progressive neuronal loss, presence of Lewy bodies and extensive non-motor symptoms found in PD. These are valuable models to advance understanding of dopaminergic neuronal death and concomitant physiological consequences but there are limits 
to what can be accomplish with neurotoxin models as they are not founded on mechanisms known to cause human PD. On the contrary, genes linked to rare forms of PD or the processes, which they regulate, are potential therapeutic targets. Studies using genetically modified animal models have implicated abnormal handling of misfolded proteins by the ubiquitin-proteasome and autophagy-lysosomal systems, increased oxidative stress, mitochondrial and lysosomal dysfunctions as key processes perturbed in the neurodegenerative process of PD. Apart from the obvious preference for vertebrate (rodents and primates) models to investigate $\mathrm{PD}$, an increasing number of studies have also shown a number of advantages and the utility of invertebrate (flies and nematodes) models. The central nervous system of invertebrate animal has a rather small number of neuron and glia as compared to vertebrates, however, essential functional features such as neurotransmitter system of vertebrates and invertebrates are conserved. However, a concern of current animal models is the ability of models to reproduce some, but not all characteristic pathological features of the human PD.

Glutathione GSH is the most abundant and the main antioxidant agent in the central nervous system. Early post-mortem studies revealed decreased levels of GSH in degenerating substantia nigra of PD patients. Although diminished GSH levels could be secondary to increased oxidative stress, it has been postulated as an early event in PD-associated neuronal death, in which the decrease in GSH content results in a direct inhibition of complex I. Decreased activity of mitochondrial complex I, found in post-mortem tissue of PD patients, is probably a founding event in neuronal death. Interestingly, this phenotype is replicated in experimental PD induced by MPTP intoxication, which induces Parkinsonian symptoms in mice, primates and humans. Inhibition of complex I leads to impaired mitochondrial adenosine triphosphate (ATP) production and an accelerated production of reactive oxygen species (ROS). The increased ROS could generate a positive loop between complex I inhibition and oxidative stress. Iron accumulation is another element relevant to neuronal death in PD. In particular, iron accumulation has been demonstrated in the dopaminergic neurons of the substantia nigra pars compacta. The iron dyshomeostasis takes place in the late stages of the disease as part of a vicious cycle resulting in uncontrolled oxidative damage. Over the years, many chemical compounds and toxin have been identified causative agents of PD. MPTP is a representative strong neurotoxin that has been recognized from several young drug addicts developed severe parkinsonism. In addition, epidemiologically, environmental neurotoxins such as agricultural chemicals (pesticides, herbicides, and fungicides) are promising candidates for causative factors of PD. Ro- tenone and paraquat could promote and accelerate the development of PD. Oxidative stress and mitochondrial dysfunction induced by these toxins could contribute to the progression of PD. While most cases of PD are sporadic, specific mutations in genes that cause familial forms of PD have led to provide new insights into its pathogenesis. Analysis of these gene products may provide vital clues to our understanding of the molecular pathogenesis of dopaminergic neuronal death in PD. Over 10 causative genes for autosomal-dominant (a-synuclein, UCHL1, and LRRK2) or autosomal-recessive (parkin, PINK1, and DJ-1) inheritance PD have been identified and classified for PARK loci.

Oxytocin and vasopressin are important modulators of diverse social and anxiety-related behaviors. The enzyme that regulates the function of both peptides, called oxitocinase $(\mathrm{OX})$ or vasopressinase, is also involved in cognitive functions. These results may reflect changes in the levels of oxytocin and vasopressin in the medial prefrontal cortex and consequently in the functions in which they are involved and might account, in part, for the cognitive abnormalities observed in hemi-Parkinsonism.

6-Hydroxydopamine (6-OHDA) is a specific dopaminergic neurotoxin and has been commonly used to produce experimental animal models of PD. The stereotaxic injection of 6-OHDA into the substantia nigra and striatum of the brain injures dopaminergic neurons. Gynostemma pentaphyllum (Cucurbitaceae, GP) is usually used as an herbal tea and is widely believed to have various protective and/or improving functions for diabetes, depression, anxiety, fatigue and hyperlipidemia. GP has been also found to have an anti-stress function and immunomodulatory activity in mice. Recently, it is reported that an oral administration of GP extracts amelioration and reduction of tyrosine hydroxylase (TH)-immunopositive cells induced by 6-OHDA-lesioning in the dopaminergic neurons of substantia nigra of rat brain.

Human leucine-rich-repeat kinase 2 (LRRK2) has been found to be thus for the most frequent cause of lateonset and idiopathic PD. The mutations are found in 5\% - $6 \%$ of patients with familial PD, and importantly also have been implicated with sporadic PD with unprecedented $1 \%$ - $2 \%$ prevalence. The pathogenic role and associated biochemical pathways responsible for LRRK2linked disease remain unknown. However the described disease-linked mutations represent a unique opportunity to biochemically explores the pathogenicity of LRRK2 and identifies therapeutic targets for related neurodegenerative disorders. Since LRRK2 kinase activity is critically linked to toxicity, it presents a viable target for therapeutic modulation.

Two of the cardinal characteristics of PD are the death of dopaminergic neurons in the substantia nigra pars 
compacta and the presence of intracellular inclusions in surviving neurons. Although a direct link between the two events is unclear, it is generally thought that these inclusions, referred to as Lewy bodies, are either causal or predictive of the oncoming neuronal death cascade. It is the loss of these dopaminergic neurons that lead to the disruptions in basal ganglia circuitry and cause the gross motor dysfunction seen in those afflicted with PD. As such, a better understanding of the components of Lewy bodies and how they may contribute to PD pathology is important. The main component of Lewy bodies is a protein known as $\alpha$-synuclein. Aside from its prominence in Lewy bodies, $\alpha$-synuclein is of particular interest because genetic mutations such as gene multiplication and amino-acid substitutions cause autosomal-dominant inherited forms of the disease. Manipulation of $\alpha$-synuclein gene expression is the basis for many experimental transgenic PD models and a target for therapeutic intervention in humans. There is also evidence to suggest that the smaller, oligomeric aggregates of $\alpha$-synuclein may be more cytotoxic than bona fide Lewy bodies. However, there is still much left to be uncovered regarding how $\alpha$-synuclein contributes to the progression of PD or even regarding the normal function of the protein. A clue to the answers for both of these questions may lie in the ability of $\alpha$-synuclein to switch between a membranebound and a cytosolic form. Pathologically, the balance between the populations of membrane-bound and cytosolic forms is thought to be important in the development of oligomeric species and/or Lewy bodies.

Current symptomatic treatment methods based on administration of L-3, 4-dihydroxyphenylalanine (L-DOPA) and other drugs that stimulate dopaminergic neurotransmission result in dyskinesia and psychiatric complications. As such, there are no effective neuroprotective or neurorestorative therapies. Recently, a novel class of compounds called neuroimmunophilin (NIL) ligands derived from the natural product FK506 (tacrolimus) have shown efficacy in treatment in a number of neurodegenerative disease models. The tyrosine hydroxylase $\mathrm{TH}$ protein and its regulation by phosphorylation are emerging as a promising molecular target to combat the locomotor deficits seen not only in PD but in aging as well.

[100-102] examined research that points to timing deficits in upper limb repetitive and coordinated movements in PD, when required to integrate a timing cue. Further, to evaluate how attention and processing of sensory feedback may contribute to timing control, it was taken a close look at new methodologies to investigate timing control during gait in PD. The results of these studies were discussed in terms of how timing deficits may be an important underlying factor that contributes to many of the motor symptoms seen in PD. The hy- potheses described in $[103,104]$ were that brain oxidative stress and damage are involved in the pathogenesis of PD. The peripheral markers could be a useful tool to determine the evolution of brain oxidative stress in neurological patients. The subject of [105-108] was the pathognomonic signs of dopaminergic neuron death observed in PD including inhibition of mitochondrial complex I, iron accumulation and decreased glutathione (GSH) content and the interplay between the three factors. The results in $[109,110]$ suggested that filterable nocardiae likely multiply within astrocytes, through which they may invade neurons, and play a significant role in both neuronal loss and Lewy body formation.

[111-114] ascertained that inflammation in both the periphery as well as the brain may be a major factor in the progression of PD. This research [111-114] identified the latest results on the identification of inflammatory markers in the blood of PD patients and the possibility that these may be able to traverse the blood brain barrier to initiate and propagate inflammation in the brain. A range of anti-inflammatory agents were discussed which have been shown in animal studies as well as PD patients to have a beneficial effect. [115-117] introduced the cellular functions of cyclin-dependent kinase 5 (Cdk5), in addition to summarizing existing knowledge on the involvement of Cdk5 in various aspects of PD pathology. $[118,119]$ suggested that the factors involved in regulating $\alpha$-synuclein membrane dissociation are likely to provide new insight into $\alpha$-synuclein function and its role in PD. [119-121] provided a mechanistic framework to our current understanding of the structural and molecular basis of FKBP function in neuronal cells in relation to PD. In summary, a deeper understanding of FKBP function in PD will not only open up new targets for treatment but will also aid the design of new neuroimmunophilins ligands for more effective therapeutic intervention. [122-124] summarized that enhancement of tyrosine hydroxylase TH activity is a central feature of growth factor related increases in locomotor activity and nigral DA may be critical for specific aspects of locomotor activity. [125-129] described the investigations into PD genes in Drosophila. The great insights derived from these studies into the underlying mechanisms that contribute to the progressive neurodegeneration caused by the disease and the future importance of Drosophila as a model organism to understanding the disease. Pesticides and herbicides are the most likely candidates for environmental agents associated with the pathogenesis of PD $[130,131]$. On the other hand, PD characteristics are seen in a number of familial motor disorders caused by different genetic factors. Animal models of neurodegenerative diseases, including PD, have in general been quite instructive in understanding their pathogenesis. Ideally, animal models of $\mathrm{PD}$, whether induced by environmental 
risk factors (neurotoxins) or genetic manipulations, should faithfully reproduce the clinical manifestations (behavioral abnormalities), pathological features, and molecular dysfunctions characterizing the disease. Unfortunately, animal models rarely mimic the etiology, progression, and pathology of PD completely, and in most cases, only partial insight can be gained from these studies. Despite these difficulties, animal models are considered to be very helpful in the development of therapies to treat PD. [132-135] discuss recently developed neurotoxin-induced and genetic model animals of PD.

[136-138] aimed to analyze oxytocinase (OX) or vasopressinase in the left and right medial prefrontal cortex of spontaneously hypertensive rat with left or right hemi-parkinsonism, induced by intrastriatal injections of 6-OHDA, and compared with sham controls. The studies [139-142] are focused on Dictyostelium discoideum Roco proteins which have similar domain architecture and very similar characteristics as LRRK2. The social amoeba Dictyostelium discoideum provides a well-established model to study the basic aspects of directed cell movement and development. They tried to answer key questions for the intramolecular regulation of LRRK2 and gave insight in the function of the LRR, the mechanism by which the Roc domain regulates kinase activity, the role that COR plays in this process and importantly how the PD-linked mutations alter the interactions between the different domains. [143-146] showed that striatal depletion of dopamine DA-depletion generates an abnormal circuit dynamics in the rodent striatum, basically, abnormal synchronized oscillatory activity at multiple levels of the cortico-basal ganglia loops and that dopamine receptor agonists dissolve the dominant state opens the way to create a bioassay for the testing of drugs with potential therapeutic value. The next review [147-156] focused on animal models of both toxin-induced and genetically determined PD that have provided significant insight for understanding this disease, and also discussed the validity, benefits, and limitations of representative models.

$[157,158]$ investigated the protective effects of herbal butanol extracts from GP (GT-BX) on stressful exposure and L-DOPA treatment in 6-OHDA-lesioned rat model of PD. Their results suggest that BP-BX develops the neuroprotective activity on stress- and L-DOPA-induced toxic reaction in the 6-OHDA-lesioned rat models of PD. The protection provided by acetyl-L-carnitine (ALC) offered the possibility of new therapeutic strategies for neurodegenerative diseases which can share the same final neurotoxic pathway in mitochondria [159,160]. A novel striatum-specific transcript encoding an orphan $G$ protein coupled receptor, the Gpr88, has been identified in rodent and human brains [161]. Gpr88 protein is highly concentrated throughout the striatum of rodent and primates with membrane/cytoplasmic expression in MSNs. Ultrastructural immunolabelling revealed concentration of Gpr88 at postsynaptic sites, preferentially contacted by asymmetrical excitatory axodendric synapses. Moreover, dopaminergic and cortico-striatal lesions, followed by administration of dopaminergic ligands in rats, revealed that Gpr88 expression is modulated by dopamine- and glutamate-regulated mechanisms, providing anatomical basis for potential therapeutic strategies for striatum-related motor disorders. [162-165] proposed that a combined therapy with antioxidant and high energetic agents should be provided to pre-clinical genetically individuals at risk to suffer PD to delay or to prevent motor symptoms and/or frank PD. These data may contribute to a better understanding of the inherent nutritional status, genetic predisposition and environmental agents as causative factors of PD. [132,166,167] examined the current evidence in the literature which offers insight into the premise that inflammation may either cause or be a consequence of neurodegeneration in PD and presents the immunomodulatory therapeutic strategies that are now under investigation and in clinical trials as potential neuroprotective drugs for PD. [168,169] suggested that neurotensin NTS1 activation may be involved in the etiology or progression of neurodegenerative pathologies and the treatment with selective NTS1 receptor antagonists in combination with conventional drug treatments could provide a novel therapeutic approach, especially for the treatment of PD. [170,171] offered one interesting approach using of embryonic stem cells (ESCs). ESCs could be an excellent source for cell replacement therapy of neurodegenerative medicine such as PD. [172,173] hypothesized that due to the compensatory additional release of striatal DA by remaining DA neurons early during dopaminergic degeneration, the neuropeptide, substance $\mathrm{P}$ (SP) through this positive feedback mechanism may also be locally increased within the SN. Here, SP may subsequently contribute to the activation of microglia and the dysfunction of the blood brain barrier, and thus perpetuate the ongoing degeneration of DA neurons. Thus, treatment with a tachykinin NK1 receptor antagonist may represent a novel neuroprotective therapy for PD that may slow disease progression.

The behavioral and biochemical studies presented in [174-176] suggest that noradrenaline system exerts a compensatory mechanism in PD, whereas the enhanced activation of $\alpha_{2 \mathrm{a}}$ adrenoceptors following repeated LDOPA treatment may contribute to the development of L-DOPA-induced dyskinesia. [177] described an analysis method based on radial basis function networks predictions which can predict a person's mitochondrial single nucleotide polymorphism (mtSNP) constitution and probabilities of becoming a PD patient; it may be useful in 
the initial diagnosis of various diseases. In addition, a slight decrease in cardiac uptake of 123i-metaiodobenzylguanidine (MIBG) has also been reported in some patients with Lewy body disease including PD and dementia with Lewy bodies $[178,179]$. The inclusion of 123I-MIBG myocardial scintigraphy in the clinical assessment can potentially increase the chance of correctly distinguishing Lewy body disease from the other parkinsonian syndromes, but ${ }^{123}$ I-MIBG myocardial scintigraphy may not regarded as the first and best choice of the differential diagnosis of PD from dementia with Lewy bodies.

\section{REFERENCES}

[1] Marino, S., Sessa, E., Di Lorenzo, G., Lanzafame, P. and Scullica, G., et al. (2007) Quantitative analysis of pursuit ocular movements in Parkinson's disease by using a videobased eye tracking system. European Neurology, 58, 193197. doi:10.1159/000107939

[2] Marino, S., Lanzafame, P., Sessa, E., Bramanti, A. and Bramanti, P. (2010) The effect of L-Dopa administration on pursuit ocular movements in suspected Parkinson's disease. Neurological Sciences, 31, 381-385. doi:10.1007/s10072-009-0180-1

[3] Cass, W.A., Grondin, R., Andersen, A.H., Zhang, Z., Hardy, P.A., Hussey-Andersen, L.K., Rayens, W.S., Gerhardt, G.A. and Gash, D.M. (2007) Iron accumulation in the striatum predicts aging-related decline in motor function in rhesus monkeys. Neurobiology of Aging, 28, 258-271. doi:10.1016/j.neurobiolaging.2005.12.010

[4] Schuff, N. (2009) Potential role of high-field MRI for studies in Parkinson's disease. Movement Disorders, 24, S684-S690. doi:10.1002/mds.22647

[5] Karagulle Kendi, A.T., Lehericy, S., Luciana, M., Ugurbil, K. and Tuite, P. (2008) Altered diffusion in the frontal lobe in Parkinson's disease. American Journal of Neuroradiology, 38, 501-505. doi:10.3174/ajnr.A0850

[6] Hummel, T., Witt, M., Reichmann, H., Welge-Luessen, A. and Haehner, A. (2010) Immunohistochemical, volumetric, and functional neuroimaging studies in patients with idiopathic Parkinson's Disease. Journal of the Neurological Sciences, 298, 119-122. doi:10.1016/j.jns.2009.08.026

[7] Wattendorf, E., Welge-Lüssen, A., Fiedler, K., Bilecen, D. and Wolfensberger, M., et al. (2009) Olfactory impairment predicts brain atrophy in Parkinson's disease. The Journal of Neuroscience, 29, 15410-15413. doi:10.1523/JNEUROSCI.1909-09.2009

[8] Welge-Lüssen, A., Wattendorf, E., Schwerdtfeger, U., Fuhr, P., Bilecen, D., et al. (2009) Olfactory induced brain activity in Parkinson's Disease relates to the expression of eventrelated potentials-An FMRI study. Neuroscience, 162, 537-543. doi:10.1016/j.neuroscience.2009.04.050

[9] Lukhanina, E.P., Karaban, I.N., Chivliklii, M.A., Pil'kevich, N.A. and Berezetskaya, N.M. (2010) Electromyographic manifestations of hereditary signs of extrapiramidal in- sufficiency. Neurophysiology, 42, 39-49. doi:10.1007/s11062-010-9129-5

[10] Robichaud, J. A., Pfann, K.D. and Leurgans, S., et al. (2009) Variability of EMG patterns: A potential neurophysiological marker of Parkinson's disease? Clinical Neurophysiology, 120, 390-397.

doi:10.1016/j.clinph.2008.10.015

[11] Meigal, A.I., Rissanen, S., Tarvainen, M.P., Karjalainen, P.A., Iudina-Vassel, I.A., Airaksinen, O. and Kankaanpää, M. (2009) Novel parameters of surface EMG in patients with Parkinson's disease and healthy young and old controls. Journal of Electromyography and Kinesiology, 19, e206-e213. doi:10.1016/j.jelekin.2008.02.008

[12] Talebinejad, M., Chan, A.D. and Miri, A. (2010) Fatigue estimation using a novel multi-fractal detrended fluctuation analysis-based approach. Journal of Electromyography and Kinesiology, 20, 433-439. doi:10.1016/j.jelekin.2009.06.002

[13] Ikeda, A., Shibasaki, H., Kaji, R., Terada, K., Nagamine, T., Honda, M. and Kimura, J. (1997) Dissociation between contingent negative variation $(\mathrm{CNV})$ and Bereits chaftspotential (BP) in patients with Parkinsonism. Electroencephalography and Clinical Neurophysiology, 102, 142-151. doi:10.1016/S0921-884X(96)95067-5

[14] Schmiedt, C., Meistrowitz, A., Schwendemann, G., Herrmann, M. and Basar-Eroglu, C. (2005) Theta and alpha oscillations reflect differences in memory strategy and visual discrimination performance in patients with Parkinson's disease. Neuroscience Letters, 388, 138-143. doi:10.1016/j.neulet.2005.06.049

[15] Dushanova, J., Philipova, D., Nikolova., G. (2009) Eventrelated synchronization/desynchronization during discrimination task conditions in patients with Parkinson's disease. Cellular and Molecular Neurobiology, 29, 971-980. doi:10.1007/s10571-009-9384-4

[16] Dushanova, J., Philipova, D. and Nikolova, G. (2010) Beta and gamma frequency-range abnormalities in parkinsonian patients under cognitive sensorimotor task. Journal of the Neurological Sciences, 293, 51-58. doi:10.1016/j.jns.2010.03.008

[17] Pavese, N. and Brooks, D.J. (2009) Imaging neurodegeneration in Parkinson's Disease. Biochimica et Biophysica Acta-Molecular Basis of Disease, 1792, 722-729. doi:10.1016/j.bbadis.2008.10.003

[18] Ferrer, I., Martinez, A., Blanco, R., Dalfó, E. and Carmona, M. (2011) Neuropathology of sporadic Parkinson's disease before the appearance of Parkinsonism: Preclinical Parkinson's disease. Journal of Neutral Transmission, 118, 821-839. doi:10.1007/s00702-010-0482-8

[19] Wu, Y., Le, W. and Jankovic, J. (2011) Preclinical biomarkers of Parkinson's disease. Archieves of Neurology, 68, 22-30. doi:10.1001/archneurol.2010.321

[20] Jenkins, B.G., Sanchez-Pernaute, R., Brownell, A.L., Chen, Y.C. and Isacson, O. (2004) Mapping dopamine function in primates using pharmacologic magnetic resonance imaging. The Journal of Neuroscience, 24, 9553-9560. doi:10.1523/JNEUROSCI.1558-04.2004

[21] Zhang, Z., Andersen, A.H., Ai, Y., Loveland, A., Hardy, P.A., Gerhardt, G.A. and Gash, D.M. (2006) Assessing 
nigrostriatal dysfunctions by pharmacological MRI in parkinsonian rhesus macaques. Neuroimage, 33, 636-643. doi:10.1016/j.neuroimage.2006.07.004

[22] Luan, L., Ding, F., Ai, Y., Andersen, A., Hardy, P., Forman, E., Gerhardt, G.A., Gash, D.M., Grondin, R. and Zhang, Z. (2008) Pharmacological MRI (phMRI) monitoring of treatment in hemiparkinsonian rhesus monkeys. Cell Transplant, 17, 417-425.

[23] Rasmussen Jr., I. (2010) Psychopharmacological MRI. Acta Neuropsychiatrica, 22, 38-39. doi:10.1111/j.1601-5215.2009.00432.x

[24] Kim, Y., Kim, J., Ito, K., Lim, H.-S., Cheong, H.-K., Kim, J.Y., Shin, Y.C., Kim, K.S. and Moon, Y. (1999) Idiopathic Parkinsonism with superimposed manganese exposure: Utility of positron emission tomography. Neurotoxicology, 20, 249-252.

[25] Guilarte, T.R., McGlothan, J.L., Degaonkar, M., Chen, M.K., Barker, P.B., Syversen, T. and Schneider, J.S. (2006) Evidence for cortical dysfunction and widespread manganese accumulation in the nonhuman primate brain following chronic manganese exposure: ${ }^{1} \mathrm{H}-\mathrm{MRS}$ and MRI study. Toxicological Sciences, 94, 351-358. doi:10.1093/toxsci/kfl106

[26] Jiang, Y.M., Zheng, W., Long, L.L., Zhao, W.J., Li, X.R., Mo, X.A., Lu, J., Fu, X., Li, W., Liu, S., Long, Q., Huang, J. and Pira, E. (2007) Brain magnetic resonance imaging and manganese concentrations in red blood cells of smelting workers: Search for biomarkers of manganese exposure. Neurotoxicology, 28, 126-135.

doi:10.1016/j.neuro.2006.08.005

[27] Guilarte, T.R., Burton, N.C., McGlothan, J.L., Vernia, T., Zhou, Y., Alexander, M., Pham, L., Griswold, M., Wong, D.F., Syversen, T. and Schneider, J.S. (2008) Impairment of nigrostriatal dopamine neurotransmission by manganese is mediated by presynaptic mechanism(s): Implications to manganese-induced Parkinsonism. Journal of Neurochemistry, 107, 1236-1247. doi:10.1111/j.1471-4159.2008.05695.X

[28] Chang, Y., Kim, Y., Woo, S.-T., Song, H.-J., Kim, S.H., Lee, H., Kwon, Y.J., Ahn, J.H., Park, S.-J., Chung, I.-S. and Jeong, K.S. (2009) High signal intensity on magnetic resonance imaging is a better predictor of neurobehavioral performances than blood manganese in asymptomatic welders. Neuro Toxicology, 30, 555-563. doi:10.1016/j.neuro.2009.04.002

[29] Chang, Y., Woo, S.-T., Lee, J.-J., Song, H-J., Lee, H.J., Yoo, D.-S., Kim, S.H., Lee, H., Kwon, Y.J., Ahn, H.J., Ahn, J.H., Park, S.-J., Weon, Y.C., Chung, I.-S., Jeong, K.S. and Kim, Y. (2009) Neurochemical changes in welders revealed by proton magnetic resonance spectroscopy. Neuro Toxicology, 30, 950-957. doi:10.1016/j.neuro.2009.07.008

[30] Chang, Y., Lee, J.J., Seo, J.H., Song, H.J., Kim, J.H., Bae, S.J., Ahn, J.H., Park, S.J., Jeong, K.S., Kwon. Y.J., Kim, S.H. and Kim, Y. (2010) Altered working memory process in the manganese-exposed brain. Neuroimage, 53, 12791285. doi:10.1016/j.neuroimage.2010.07.001

[31] Dydak, U., Jiang, Y.M., Long, L.L., Zhu, H., Chen, J., Li, W.M., Edden, R.A., Hu, S., Fu, X., Long, Z., Mo, X.A.,
Meier, D., Harezlak, J., Aschner, M., Murdoch, J.B. and Zheng, W. (2011) In vivo measurement of brain GABA concentrations by magnetic resonance spectroscopy in smelters occupationally exposed to manganese. Environmental Health Perspectives, 119, 219-224. doi:10.1289/ehp.1002192

[32] Kim, Y., Jeong, K.S., Song, H.-J., Lee, J.-J., Seo, J.-H., Kim, G.-C., Lee, H.J., Kim, H.J., Ahn, J.-H., Park, S.-J., Kim, S.H., Kwon, Y.J. and Chang, Y. (2011) Altered white matter microstructural integrity revealed by voxelwise analysis of diffusion tensor imaging in welders with manganese exposure. Neuro Toxicology, 32, 100-109. doi:10.1016/j.neuro.2010.11.004

[33] Speziali, M. and Orvini, E. (2003) Metals distribution and regionalization in the brain. In: Zatta, P., Ed., Metal Ions and Neurodegenerative Disorders, World Scientific Publishing Co., New Jersey, 15-65. doi:10.1142/9789812796691 0002

[34] Qureshi, G.A., Qureshi, A.A., Memon, S.A. and Parvez, S.H. (2006) Impact of selenium, iron, copper and zinc in on/off Parkinson's patients on L-dopa therapy. Journal of Neural Transmission, 71, 229-236. doi:10.1007/978-3-211-33328-0_24

[35] Tan, X., Luo, Y., Pan, J., Huang, B. and Wang P.Q. (2007) Serum $\mathrm{Cu}, \mathrm{Fe}, \mathrm{Mn}$, and $\mathrm{Zn}$ levels and Parkinson's disease. Parkinsonism \& Related Disorders, 13, S134. doi:10.1016/S1353-8020(08)70745-4

[36] Speziali, M. and Di Casa, M. (2009) Copper, iron, zinc and other element concentrations in cerebrospinal fluid of Parkinson's disease patients-Considerations on literature data. Journal of Trace Elements and Electrolytes, 26, 171-176.

[37] Ongkana, N., Tohno, S., Tohno, Y., Suwannahoy, P., Mahakkanukrauh, P., Azuma, C. and Minami, T. (2010) Agerelated changes of elements in the anterior commissures and the relationships among their elements. Biological Trace Element Research, 135, 86-97. doi:10.1007/s12011-009-8496-5

[38] Tohno, Y., Tohno, S., Ongkana, N., Suwannahoy, P., Azuma, C., Minami, T. and Mahakkanukrauh, P. (2010) Age-related changes of elements and relationships among elements in human hippocampus, dentate gyrus, and fornix. Biological Trace Element Research, 138, 42-52. doi:10.1007/s12011-009-8605-5

[39] Colman, K., Koerts, J., van Beilen, M., Leenders, K.L. and Bastiaanse, R. (2006) The role of cognitive mechanisms in sentence comprehension in dutch speaking Parkinson's disease patients: Preliminary data. Brain and Language, 99, 109-110. doi:10.1016/j.band1.2006.06.069

[40] Boulenger, V., Mechtouff, L., Thobois, S., Broussolle, E., Jeannerod, M. and Nazir, T.A. (2008) Word processing in Parkinson's disease is impaired for action verbs but not for concrete nouns. Neuropsychologia, 46, 743-756. doi:10.1016/j.neuropsychologia.2007.10.007

[41] Colman, K.S.F., Koerts, J., van Beilen, M., Leenders, K.L., Post, W. J. and Bastiaanse, R. (2009) The impact of executive functions on verb production in patients with Parkinson's Disease. Cortex, 45, 930-942. doi:10.1016/j.cortex.2008.12.010 
[42] McKinlay, A., Dalrymple-Alford, J.C., Grace, R.C. and Roger, D. (2009) The effect of attentional set-shifting, working memory, and processing speed on pragmatic language functioning in Parkinson's Disease. European Journal of Cognitive Psychology, 21, 330-346. doi:10.1080/09541440802281266

[43] Kandori, A., Yokoe, M., Sakoda, S., Abe, K., Miyashita, T., Oe, H., Naritomi, H., Ogata, K. and Tsukada, K. (2004) Quantitative magnetic detection of finger movements in patients with Parkinson's disease, Neuroscience Research, 49, 253-260. doi:10.1016/j.neures.2004.03.004

[44] Endo, T., Okuno, R., Yokoe, M., Akazawa, K. and Sakoda, S. (2009) A novel method for systematic analysis of rigidity in Parkinson's disease. Movement Disorders, 24, 2218-2224. doi: $10.1002 / \mathrm{mds} .22752$

[45] Yokoe, M., Okuno, R., Hamasaki, T., Kurachi, Y., Akazawa, K. and Sakoda, S. (2009) Opening velocity, a novel parameter, for finger tapping test in patients with Parkinson's Disease, Parkinsonism \& Related Disorders, 15, 440-444. doi:10.1016/j.parkreldis.2008.11.003

[46] Yuceturk, A.V., Yilmaz, H., Egrilmez, M., Karaca, S. (2002) Voice analysis and videolaryngostroboscopy in patients with Parkinson's disease. European Archives of Otorhinolaryngol, 259, 290-293.

[47] Harel, B., Cannizzaro, M., Snyder, P.J. (2004) Variability in fundamental frequency during speech in prodromal and incipient Parkinson's disease: A longitudinal case study. Brain Cognition, 56, 24-29. doi:10.1016/j.bandc.2004.05.002

[48] Sapir, S., Spielman, J., Ramig, L., Story, B., Fox, C. (2007) Effects of intensive voice treatment $\left(\right.$ LSVT $\left.^{\mathbb{R}}\right)$ on vowel articulation in dysarthric individuals with idiopathic Parkinson's disease: Acoustic and perceptual findings. Journal of Speech, Language, and Hearing Research, 50, 899-912. doi:10.1044/1092-4388(2007/064)

[49] Yamamoto, Y., Struzik, Z.R., Soma, R., Ohashi, K. and Kwak, S. (2005) Noisy vestibular stimulation improves autonomic and motor responsiveness in central neurodegenerative disorders. Annals of Neurology, 58, 175-181. doi:10.1002/ana.20574

[50] Pan, W., Ohashi, K., Yamamoto, Y. and Kwak, S. (2007) Power-law temporal autocorrelation of activity reflects severity of parkinsonism. Movement Disorders, 22, 13081313. doi: $10.1002 / \mathrm{mds} .21527$

[51] Pan, W., Soma, R., Kwak, S. and Yamamoto, Y. (2008) Improvement of motor functions by noisy vestibular stimulation in central neurodegenerative disorders. Journal of Neurology, 255, 1657-1661. doi:10.1007/s00415-008-0950-3

[52] Vaugoyeau, M., Viel, S., Assaiante, C., Amblard, B. and Azulay, J.P. (2007) Impaired vertical postural control and proprioceptive integration deficits in Parkinson's disease. Neuroscience, 146, 852-863. doi:10.1016/j.neuroscience.2007.01.052

[53] Hayashi, R., Aizawa, J., Nagase, H., Ohara, S. (2010) Lateral inclination of the trunk and falling frequency in Parkinson's disease patients. Electromyography and Clinical Neurophysiology, 50, 195-202.

[54] Johnson, A.M., Pollard, C.C., Vernon, P.A., Tomes, J.L. amd Jog, M.S. (2005) Memory perception and strategy use in Parlinson's disease. Parkinsonism \& Related Disorders , 1, 111-115. doi:10.1016/j.parkreldis.2004.06.005

[55] Yogev, G., Giladi, N., Peretz, C., Springer, S., Simon, E.S. and Hausdorff, J.M. (2005). Dual tasking, gait rhythmicity, and Parkinson's disease: Which aspects of gait are attention demanding? European Journal of Neuroscience, 22, 1248-1256. doi:10.1111/j.1460-9568.2005.04298.x

[56] Goebel, S., Mehdorn, H.M. and Leplow, B. (2010) Strategy instruction in Parkinson's disease: Influence on cognitive performance. Neuropsychologia, 48, 574-580. doi:10.1016/j.neuropsychologia.2009.10.020

[57] Aarsland, D., Brønnick, K. and Fladby, T. (2011) Mild cognitive impairment in Parkinson's disease. Current Neurology and Neuroscience Reports, 11, 371-378. doi:10.1007/s11910-011-0203-1

[58] Patel, S., Lorincz, K., Hughes, R., Huggins, N., Growdon, J., Standaert, D. (2009) Monitoring motor fluctuations in patients with Parkinson's disease using wearable sensors. IEEE Transactions on Information Technology in Biomedicine, 13, 864-873. doi:10.1109/TITB.2009.2033471

[59] Tindall, L.R. and Huebner, R.A. (2009) The Impact of an application of telerehabilitation technology on caregiver burden. International Journal of Telerehabilitation, 1, 3-8. doi:10.5195/ijt.2009.5559

[60] Papapetropoulos, S., Heather, K., Scanlo, B.K., Guevara, A., Singer, C. and Levin, B. (2010) Objective quantification of neuromotor symptoms in Parkinson's disease: Implementation of a portable, computerized measurement tool. Parkinson's Disease, 760196.

[61] Patel, S., Buckley, T., Rednic, R., McClure, D., Shih, L., Tarsy, D., et al. (2010) A web-based system for home monitoring of patients with Parkinson's disease using wearable sensors. IEEE Transactions on Biomedical Engineering, 58, 831-836.

[62] Westin, J., Dougherty, M., Nyholm, D. and Groth, T. (2010) A home environment test battery for status assessment in patients with advanced Parkinson's disease. Computer Methods and Programs in Biomedicine, 98, 27-35. doi:10.1016/j.cmpb.2009.08.001

[63] Devos, H., Vandenberghe, W., Nieuwboer, A., Tant, M., Baten, G. and De Weerdt, W. (2007) Predictors of fitness to drive in people with Parkinson's disease. Neurology, 69,1434-1441. doi:10.1212/01.wnl.0000277640.58685.fc

[64] Cordell, R., Lee, H.C., Granger, A., Vieira, B. and Lee, A.H. (2008) Driving assessment in Parkinson's disease: A novel predictor of performance. Movement Disorders, 23, 1217-1222. doi: $10.1002 / \mathrm{mds} .21762$

[65] Uc, E.Y., Rizzo, M., Johnson, J.E., Dastrup, E., Anderson, S.W. and Dawson, J. (2009) Road safety in drivers with Parkinson's Disease. Neurology, 73, 2112-2119. doi:10.1212/WNL.0b013e3181c67b77

[66] Uitti, R.J. (2009) Parkinson's Disease and issues related to driving. Parkinsonism \& Related Disorders, 15, S122S125.

[67] Gobbi, L., Oliveira-Ferreira, M.D., Caetano, M.J., LiraniSilva, E., Barbieri, F., Stella, F. and Gobbi, S. (2009) Exercise programs improve mobility and balance in people 
with Parkinson's disease. Parkinsonism \& Related Disorders, 15, S49-S52. doi:10.1016/S1353-8020(09)70780-1

[68] Sage, M. and Almeida, Q. (2009) Symptom and gait changes after sensory attention focused exercise vs aerobic training in Parkinson's disease. Movement Disorders, 24, 1132-1138. doi: $10.1002 / \mathrm{mds} .22469$

[69] Tanaka, K., Quadros, A.C., Jr., Santos, R., Stella, F., Gobbi, L. and Gobbi, S. (2009) Benefits of physical exercise on executive functions in older people with Parkinson's Disease. Brain and Cognition, 69, 435-441. doi:10.1016/j.bandc.2008.09.008

[70] Hackney, M. and Earhart, G. (2010) Effects of dance on gait and balance in Parkinson's disease: A comparison of partnered and nonpartnered dance movement. Neurorehabilitation and Neural Repair, 24, 384-392.

[71] Sage, M. and Almeida, Q. (2010) A positive influence of vision on motor symptoms during sensory attention focused exercise for Parkinson's Disease. Movement Disorders, 25, 64-69.

[72] Beijer, L., Rietveld, T., Hoskam, V., Geurts, A. and de Swart, B. (2010) Evaluating the feasibility and the potential efficacy of e-learning-based speech therapy for speech training in dysarthric patients with Parkinson's Disease: A case study. Telemedicine and E-Health, 16, 732-738.

[73] Ellis, T., de Goede, C.J., Feldman, R.G., Wolters, E.C., Kwakkel, G. and Wagenaar, R.C. (2005) Efficacy of a physical therapy program in patients with Parkinson's disease: A randomized controlled trial. Archives of Physical Medicine and Rehabilitation, 86, 626-632. doi:10.1016/j.apmr.2004.08.008

[74] Lun, V., Pullan, N., Labelle, N., Adams, C. and Suchowersky, O. (2005) Comparison of the effects of a selfsupervised home exercise program with a physiotherapist supervised exercise program on the motor symptoms of Parkinson's disease. Movement Disorders, 20, 971-975. doi:10.1002/mds. 20475

[75] Keus, S., Bloem, B.R., Hendriks, E., Bredero-Cohen, A. and Munneke, M. (2007) Evidence-based analysis of physical therapy in Parkinson's disease with recommendations for practice and research. Movement Disorders, 22, 451-460. doi:10.1002/mds.21244

[76] Brichetto,G., Pelosin, E., Marchese, R. and Abbruzzese, G. (2006) Evaluation of physical therapy in parkinsonian patients with freezing of gait: A pilot study. Clinical Rehabilitation, 20, 31-35. doi:10.1191/0269215506cr913oa

[77] Schmitz-Hübsch, T., Pyfer, D., Kielwein, K., Fimmers, R., Klockgether, T. and Wüllner, U. (2006) Qigong exercise for the symptoms of Parkinson's Disease: A randomized, controlled pilot study. Movement Disorders, 21, 543-548. doi: $10.1002 / \mathrm{mds} .20705$

[78] Herman, T., Giladi, N., Gruendlinger, L. and Hausdorff, J.M. (2007) Six weeks of intensive treadmill training improves gait and quality of life in patients with Parkinson's disease: A pilot study. Archives of Physical Medicine and Rehabilitation, 88, 1154-1158. doi:10.1016/j.apmr.2007.05.015

[79] Jöbges, E., Spittler-Schneiders, H., Renner, C. and Hummelsheim, H. (2007) Clinical relevance of rehabilitation programs for patients with idiopathic Parkinson syndrome II: Symptom-specific therapeutic approaches. Parkinsonism \& Related Disorders, 13, 203-213. doi:10.1016/j.parkreldis.2006.07.018

[80] Takahashi, Y., Osamu, N. and Komeda, T. (2008) Development of a sit-to-stand assistance system. Lecture Notes in Computer Science, 5105, 1277-1284. doi:10.1007/978-3-540-70540-6 191

[81] Costa, J., Valls-Sole, J., Valldeoriola, F., Pech, C. and Rumia, J. (2006) Single subthalamic nucleus deep brain stimuli inhibit the blink reflex in Parkinson's disease patients. Brain, 129, 1758-1767. doi:10.1093/brain/aw1143

[82] Costa, J., Valls-Sole, J., Valldeoriola, F., Rumia, J. and Tolosa, E. (2007) Motor responses of muscles supplied by cranial nerves to subthalamic nucleus deep brain stimuli. Brain, 130, 245-255. doi:10.1093/brain/awl336

[83] Valls-Solé, J., Compta, Y., Costa, J., Valldeoriola, F. and Rumià, J. (2008) Human central nervous system circuits examined through the electrodes implanted for deep brain stimulation. Clinical Neurophysiology,119, 1219-1231. doi:10.1016/j.clinph.2007.12.020

[84] Alessandro, S., Ceravolo, R., Brusa, L., Pierantozzi, M., Costa, A., Galati, S., Placidi, F., Romigi, A., Iani, C., Marzetti, F. and Peppe, A. (2010) Non-motor functions in parkinsonian patients implanted in the pedunculopontine nucleus: Focus on sleep and cognitive domains. Journal of the Neurological Sciences, 289, 44-48. doi:10.1016/i.jns.2009.08.017

[85] Kim, H.J., Jeon, B.S., Paek, S.H., Lee, J.Y., Kim, H.J., Kim, C.K. and Kim, D.G. (2010) Bilateral subthalamic deep brain stimulation in Parkinson disease patients with se- vere tremor. Neurosurgery, 67, 626-632. doi:10.1227/01.NEU.0000374850.98949.D4

[86] Lee, J.Y., Kim, J.W., Lee, J.Y., Lim, Y.H., Kim, C., Kim, D.G., Jeon, B.S. and Paek, S.H. (2010) Is MRI a reliable tool to locate the electrode after deep brain stimulation sur- gery? Comparison study of CT and MRI for the localization of electrodes after DBS. Acta Neurochirurgica, 152, 2029-2036. doi:10.1007/s00701-010-0779-2

[87] Paek, S.H., Han, J.H., Lee, J.Y., Kim, C., Jeon, B.S. and Kim, D.G. (2008) Electrode position determined by fused images of preoperative and postoperative magnetic resonance imaging and surgical outcome after subthalamic nucleus deep brain stimulation. Neurosurgery, 63, 925937. doi:10.1227/01.NEU.0000334045.43940.FB

[88] Cho, Z.H., Min, H.K., Oh, S.H., Han, J.Y., Park, C.W., Chi, J.G., Kim, Y.B., Paek, S.H., Lozano, A.M. and Lee, K.H. (2010) Direct visualization of deep brain stimulation targets in Parkinson's disease with the use of 7-tesla magnetic resonance imaging. Journal of Neurosurgery, 113, 639-647. doi:10.3171/2010.3.JNS091385

[89] Paek, S.H., Kim, J.W., Lim, Y.H., Kim, M.R., Kim, D.G. and Jeon, B.S. (2010) Data management system in a movement disorder center: Technical report. Stereotactic and Functional Neurosurgery, 88, 216-223. doi: $10.1159 / 000314356$

[90] Paek, S.H., Kim, H.J., Yoon, J.Y., Heo, J.H., Kim, C.Y., Kim, M.R., Lim, Y.H., Kim, K.R., Han, J.H., Kim, D.G. 
and Jeon, B.S. (2011) Fusion image-based programming after subthalamic nucleus deep brain stimulation. World Neurosurgery ,75, 517-524. doi:10.1016/j.wneu.2010.12.003

[91] Tani, N., Saitoh, Y., Kishima, H., Oshino, S., Hatazawa, J., Hashikawa, K. and Yoshimine, T. (2007) Motor cortex stimulation for levodopa-resistant akinesia: Case report. Movement Disorders, 22, 1645-1649. doi:10.1002/mds. 21593

[92] Saitoh, Y. and Hosomi, K. (2009) From localization to surgical implantation. In: Canavero, S., Ed., Textbook of Therapeutic Cortical Stimulation, Nova Science Publishers, Inc., New York.

[93] Kryzak, T.J., Sperling, J.W., Schleck, C.D. and Cofield, R. H. (2009) Total shoulder arthroplasty in patients with Parkinson's Disease. Journal of Shoulder and Elbow Surgery, 18, 96-99. doi:10.1016/j.jse.2008.07.010

[94] Kryzak, T.J., Sperling, J.W., Schleck, C.D. and Cofield, R.H. (2010) Hemiarthroplasty for proximal humerus fractures in patients with Parkinson's Disease. Clinical Orthopaedics and Related Research, 468, 1817-1821. doi:10.1007/s11999-010-1353-1

[95] Greffard, S., Verny, M., Bonnet, A.M., Seilhean, D., Hauw, J.J. and Duyckaerts, C. (2010) A stable proportion of lewy body bearing neurons in the substantia nigra suggests a model in which the lewy body causes neuronal death. Neurobiology Aging, 31, 99-103. doi:10.1016/i.neurobiolaging.2008.03.015

[96] Li, J.Y., Englund, E., Widner, H., Rehncrona, S., Björklund, A., Lindvall, O. and Brundin, P. (2010) Characterization of lewy body pathology in 12- and 16-year-old intrastriatal mesencephalic grafts surviving in a patient with Parkinson's disease. Movement Disorders, 25, 1091-1096. doi: $10.1002 / \mathrm{mds} .23012$

[97] Stocchi, F., Rascol, O., Kieburtz, K., Poewe, W., Jankovic, J., Tolosa, E., Barone, P., Lang, A.E. and Olanow, C.W. (2010) Initiating levodopa/carbidopa therapy with and without entacapone in early Parkinson disease: The STRIDE-PD study. Annals of Neurology, 68, 18-27. doi:10.1002/ana.22060

[98] Hauser, R.A, Schapira, A.H., Rascol, O., Barone, P., Mizuno, Y., Salin, L., Haaksma, M., Juhel, N. and Poewe, W. (2010) Randomized, double-blind, multicenter evaluation of pramipexole extended release once daily in early Parkinson's Disease. Movement Disorders, 25, 2542-2549. doi: $10.1002 / \mathrm{mds} .23317$

[99] Marks, W.J., Bartus, R.T., Siffert, J., Davis, C.S., Lozano, A., Boulis, N., Vitek, J., Stacy, M., Turner, D., Verhagen, L., Bakay, R., Watts, R., Guthrie, B., Jankovic, J., Simpson, R., Tagliati, M., Alterman, R., Stern, M., Baltuch, G., Starr, P.A., Larson, P.S., Ostrem, J.L., Nutt, J., Kieburtz, K., Kordower, J.H. and Olanow, C.W. (2010) Gene delivery of AAV2-neurturin for Parkinson's disease: A double-blind, randomised, controlled trial. The Lancet Neurology, 9, 1164-1172. doi:10.1016/S1474-4422(10)70254-4

[100] Almeida, Q.J., Frank, J.S., Roy, E.A., Patla, A.E., and Jog, M.S. (2007) Dopaminergic modulation of timing control and variability in the gait of Parkinson's disease. Movement Disorders, 22, 1735-1742. doi:10.1002/mds.21603
[101] Almeida, Q.J. and Lebold, C.A. (2010) Freezing of gait in Parkinson's disease: A perceptual cause for a motor impairment? Journal of Neurology, Neurosurgery \& Psychiatry, 81, 513-518. doi:10.1136/jnnp.2008.160580

[102] Brown, M.J. and Almeida, Q.J. (2011) Evaluating dopaminergic system contributions to cued pattern switching during bimanual coordination. European Journal of Neuroscience, 34, 632-640. doi:10.1111/j.1460-9568.2011.07773.x

[103] Serra, J.A., Domínguez, R.O., Marschoff, E.R., Guareschi E.M., Famulari, A.L. and Boveris, A. (2009) Systemic oxidative stress associated with the neurological diseases of aging. Neurochemical Research, 34, 2122-2132. doi:10.1007/s11064-009-9997-5

[104] Farooqui, T. and Farooqui, A. (2011) Lipid-mediated oxidative stress and inflammation in the pathogenesis of Parkinson's disease. Parkinson's Disease, 247467

[105] Kaur, D., Lee, D., Ragapolan, S. and Andersen, J.K. (2009) Glutathione depletion in immortalized midbrainderived dopaminergic neurons results in increases in the labile iron pool: Implications for Parkinson's disease. Free Radical Biology \& Medicine, 46, 593-598. doi:10.1016/j.freeradbiomed.2008.11.012

[106] Lee, D.W., Kaur, D., Chinta, S.J., Rajagopalan, S. and Andersen, J.K. (2009) A disruption in iron-sulfur center biogenesis via inhibition of mitochondrial dithiol glutaredoxin 2 may contribute to mitochondrial and cellular iron dysregulation in mammalian glutathione-depleted dopaminergic cells: Implications for Parkinson's disease. Antioxid \& Redox Signaling, 11, 2083-2094. doi:10.1089/ars.2009.2489

[107] Gomez, F.J., Aguirre, P., Gonzalez-Billault, C. and Núñez, M.T. (2011) Iron mediates neuritic tree collapse in mesencephalic neurons treated with 1-methyl-4-phenylpyridinium (MPP+). Journal of Neural Transmission, 118, 421431. doi:10.1007/s00702-010-0489-1

[108] Pelizzoni, I., Macco, R., Morini, M.F., Zacchetti, D., Grohovaz, F. and Codazzi, F. (2011). Iron handling in hippocampal neurons: activity-dependent iron entry and mitochondria-mediated neurotoxicity. Aging Cell, 10, 172183. doi:10.1111/j.1474-9726.2010.00652.x

[109] Kohbata, S. and Shimokawa, K. (1993) Circulating antibody to Nocardia in the serum of patients with Parkinson's disease. Advances in Neurology, 60, 355-357.

[110] Kohbata, S., Tamura, T. and Hayashi, R. (1998) Accumulation of acid-fast lipochrome bodies in glial cells of the midbrain nigral lesion in Parkinson's Disease. Clinical and Diagnositic Laboratory Immunology, 5, 888-893.

[111] Crichton, R.R., Dexter, D.T. and Ward, R.J. (2008) Molecular-based neurodegenerative diseases: From molecular mechanisms to therapeutic strategies Coordination Chemistry Reviews, 252, 1189-1199. doi:10.1016/i.ccr.2007.10.019

[112] Marinova-Mutafchieva, L., Sadeghian, M., Broom, L., Davis, J.B., Medhurst, A.D. and Dexter, D.T. (2009) Relationship between microglial activation and dopaminergic neuronal loss in the substantia nigra: A time course study in a 6-hydroxydopamine model of Parkinson's disease. Journal of Neurochemistry, 110, 966-975. 
doi:10.1111/j.1471-4159.2009.06189.x

[113] Dexter, D.T., Statton, S.A., Whitmore, C., Freinbichler, W., Weinberger, P., Tipton, K.T., Della Corte, L., Ward, R.J. and Crichton, R.R. (2011) Clinically available iron chelators induce neuroprotection in the 6-OHDA model of Parkinson's disease after periphereal administration. Journal of Neural Transmission, 118, 223-231. doi:10.1007/s00702-010-0531-3

[114] Ward, R.J., Lallemand, F., De Witte, P., Crichton, R.R., Piette, J., Della Corte, L., Hemmings, K., Page, M., Taylor, D. and Dexter, D.T. (2011) Anti-inflammatory actions of taurine analogues in phagocytic cells. Biochemical Pharmacology, 81, 743-751. doi:10.1016/j.bcp.2010.12.030

[115] Cheung, Z.H. and Ip, N.Y. (2009) The emerging role of autophagy in Parkinson's disease. Molecular Brain, 2, 29. doi:10.1186/1756-6606-2-29

[116] Lai, K.O. and Ip, N.Y. (2009) Recent advances in understanding the roles of Cdk5 in synaptic plasticity. Biochimica et Biophysica Acta, 1792, 741-745. doi:10.1016/j.bbadis.2009.05.001

[117] Gorbatyuk, O.S., Li, S., Sullivan, L.F., Chen, W., Kondrikova, G., Manfredsson, F.P., Mandel, R.J. and Muzyczka, N. (2008) The phosphorylation state of Ser-129 in human alpha-synuclein determines neurodegeneration in a rat model of Parkinson disease. Proceeding of the National Academy of Sciences USA, 105, 763-768.

[118] Nakamura, K., Nemani, V.M., Azarbal, F., Skibinski, G., Levy, J.M., Egami, K., Munishkina, L., Zhang, J., Gardner, B., Wakabayashi, J., Sesaki, H., Cheng, Y., Finkbeiner, S., Nussbaum, R.L., Masliah, E. and Edwards, R.H. (2011) Direct membrane association drives mitochondrial fission by the Parkinson Disease-associated protein \{alpha\}-synuclein. The Journal of Biological Chemistry, 286, 20710-20726. doi:10.1074/jbc.M110.213538

[119] Muntane, G., Dalfo, E., Martinez, A. and Ferrer, I. (2008) Phosphorylation of tau and alpha-synuclein in synapticenriched fractions of the frontal cortex in Alzheimer's disease and in Parkinson's disease and related alphasynucleinopathies. Neuroscience, 152, 913-923. doi:10.1016/j.neuroscience.2008.01.030

[120] Chambraud, B., Sardin, E., Giustiniani, J., Dounane, O., Schumacher, M., Goedert, M. and Baulieu, E.E. (2010). A role for FKBP52 in Tau protein function. Proceeding of the National Academy of Sciences USA, 107, 2658-2663. doi:10.1073/pnas.0914957107

[121] Fusco, D., Vargiolu, M., Vidone, M., Mariani, E., Pennisi, L.F., Bonora, E., Capellari, S., Dirnberger, D., Baumeister, R., Martinelli, P. and Romeo, G. (2010) The RET51/ FKBP52 complex and its involvement in Parkinson disease. Human Molecular Genetics, 19, 2804-2816. doi:10.1093/hmg/ddq181

[122] Schuster, S., Nadjar, A., Guo, J.T., Li, Q., Ittrich, C., Hengerer, B. and Bezard, E. (2008) The 3-hydroxy-3methylglutaryl-CoA reductase inhibitor lovastatin reduces severity of LDOPA-induced abnormal involuntary movements in experimental Parkinson's disease. Journal of Neuroscience, 28, 4311-4316. doi:10.1523/JNEUROSCI.4720-07.2008
[123] Salvatore, M.F., Pruett, B.S., Spann, S.L. and Dempsey, C. (2009) Aging reveals a role for nigral tyrosine hydroxylase ser31 phosphorylation in locomotor activity generation. PLOS ONE, 4, e8466. doi:10.1371/journal.pone.0008466

[124] Pruett, B.S. and Salvatore, M.F. (2010) GFR $\alpha-1$ receptor expression in the aging nigrostriatal and mesoaccumbens pathways. Journal of Neurochemistry, 115, 707-715. doi:10.1111/j.1471-4159.2010.06963.x

[125] Todd, A.M. and Staveley, B.E. (2008) Pink1 suppresses alpha-synuclein-induced phenotypes in a Drosophila model of Parkinson's disease. Genome, 51, 1040-1046. doi:10.1139/G08-085

[126] Botella, J.A., Bayersdorfer, F. and Schneuwly, S. (2008) Superoxide dismutase overexpression protects dopaminergic neurons in a Drosophila model of Parkinson's disease. Neurobiology of Disease, 30, 65-73. doi:10.1016/j.nbd.2007.11.013

[127] Deng, H., Dodson, M.W., Huang, H. and Guo, M. (2008) The Parkinson's disease genes pink1 and parkin promote mitochondrial fission and/or inhibit fusion in Drosophila. Proceedings of the National Academy Science USA, 105, 14503-14508. doi:10.1073/pnas.0803998105

[128] Liu, Z., Wang, X., Yu, Y., Li, X., Wang, T., Jiang, H., Ren, Q., Jiao, Y., Sawa, A., Moran, T., Ross, C.A., Montell, C. and Smith, W.W. (2008) A Drosophila model for LRRK2linked parkinsonism. Proceedings of the National Academy Science USA, 105, 2693-2398.

[129] Trinh, K., Moore, K., Wes, P.D., Muchowski, P.J., Dey, J., Andrews, L. and Pallanck, L.J. (2008) Induction of the phase II detoxification pathway suppresses neuron loss in Drosophila models of Parkinson's disease. Journal of Neuroscience, 28, 465-472. doi:10.1523/JNEUROSCI.4778-07.2008

[130] Tanner, C.M. (2003) Is the cause of Parkinson's disease environmental or hereditary? Evidence from twin studies. Advances in Neurology, 91, 133-142.

[131] Dick, F.D., et al. (2007) Environmental risk factors for Parkinson's disease and Parkinsonism: The Geoparkinson study. Occupational and Environmental Medicine, 64, 666672. doi:10.1136/oem.2006.027003

[132] Crotty, S., Fitzgerald, P., Tuohy, E., Harris, D.M., Fisher, A., Mandel, A., Bolton, A.E., Sullivan, A.M. and Nolan, Y. (2008) Neuroprotective effects of novel phosphatidylglycerol-based phospholipids in the 6-hydroxydopamine model of Parkinson's disease. European Journal of Neuroscience, 27, 294-300. doi:10.1111/j.1460-9568.2007.06018.x

[133] Gasser, T. (2009) Molecular pathogenesis of Parkinson disease: Insights from genetic studies. Expert Reviews in Molecular Medicine, 11, e22. doi:10.1017/S1462399409001148

[134] Lees, A.J., Hardy, J. and Revesz, T. (2009) Parkinson's disease. Lancet, 373, 2055-2066. doi:10.1016/S0140-6736(09)60492-X

[135] Borah, A. and Mohanakumar, K.P. (2010). L-DOPAinduced 6-hydroxydopamine production in the striata of rodents is sensitive to the degree of denervation. Neuro- 
chemistry International, 56, 357-362. doi:10.1016/j.neuint.2009.11.008

[136] Banegas, I., Prieto, I., Alba, F., Vives, F., Araque, A., Segarra, A.B., Durán, R., de Gasparo, M. and Ramírez, M. (2005) Angiotensinase activity is asymmetrically distributed in the amygdala, hippocampus and prefrontal cortex of the rat. Behavioural Brain Research, 156, 321-326. doi:10.1016/j.bbr.2004.06.002

[137] Banegas, I., Prieto, I., Vives, F., Alba, F., de Gasparo, M., Duran, R., Luna, J. de D., Segarra, A.B., Hermoso, F. and Ramírez, M. (2009) Asymmetrical response of aminopeptidase A and nitric oxide in plasma of normotensive and hypertensive rats with experimental hemiparkinsonism. Neuropharmacology, 56, 573-579. doi:10.1016/j.neuropharm.2008.10.011

[138] Banegas, I., Prieto, I., Vives, F., Alba, F., de Gasparo, M., Duran, R., Segarra, A.B. and Ramírez, M. (2010) Lateralized response of oxytocinase activity in the medial prefrontal cortex of a unilateral rat model of Parkinson's disease. Behavioural Brain Research, 213, 328-331. doi:10.1016/j.bbr.2010.05.030

[139] Gotthardt, K., Weyand, M., Kortholt, A., van Haastert, P.J. and Wittinghofer, A. (2008) Structure of the Roc-COR domain tandem of $C$. tepidum, a prokaryotic homologue of the human LRRK2 Parkinson kinase. The EMBO Journal, 27, 2239-2249. doi:10.1038/emboj.2008.150

[140] van Egmond, W.N., Kortholt, A., Plak, K., Bosgraaf, L., Bosgraaf, S., Keizer-Gunnink, I. and van Haastert, P.J. (2008) Intramolecular activation mechanism of the Dictyostelium LRRK2 homolog Roco protein GbpC. The Journal of Biological Chemistry, 283, 30412-30420. doi:10.1074/jbc.M804265200

[141] van Egmond, W.N. and van Haastert, P.J. (2010) Characterization of the Roco protein family in Dictyostelium discoideum. Eukaryot Cell, 9, 751-761. doi:10.1128/EC.00366-09

[142] Araki, T., van Egmond, W.N., van Haastert, P.J. and Williams, J.G. (2010) Dual regulation of a Dictyostelium STAT by cGMP and $\mathrm{Ca}^{2+}$ signalling. Journal of Cell Science, 123, 837-841. doi:10.1242/jcs.064436

[143] Ibáñez-Sandoval, O., Carrillo-Reid, L., Galarraga, E., Tapia, D., Mendoza, E., Gomora, J.C., Aceves, J. and Bargas, J. (2007) Bursting in substantia nigra pars reticulata neurons in vitro: Possible relevance for Parkinson disease. Journal of Neurophysiology, 98, 2311-2323. doi:10.1152/jn.00620.2007

[144] Carrillo-Reid, L., Tecuapetla, F., Tapia, D., HernandezCruz, A., Galarraga, E., Drucker-Colin, R. and Bargas, J. (2008) Encoding network states by striatal cell assemblies. Journal of Neurophysiology, 99, 1435-1450. doi:10.1152/jn.01131.2007

[145] Li, X., Ouyang, G., Usami, A., Ikegaya, Y. and Sik, A. (2010) Scale-free topology of the CA3 hippocampal network: A novel method to analyze functional neuronal assemblies. Biophysical Journal, 98, 1733-1741. doi:10.1016/j.bpj.2010.01.013

[146] Jaidar, O., Carrillo-Reid, L., Hernandez, A., DruckerColin, R., Bargas, J. and Hernandez-Cruz, A. (2010) Dynamics of the Parkinsonian striatal microcircuit: Entrain- ment into a dominant network state. Journal of Neuroscience, 30, 11326-11336.

doi:10.1523/JNEUROSCI.1380-10.2010

[147] Goldberg, M.S., Pisani, A., Haburcak, M., Vortherms, T.A., Kitada, T., Costa, C., Tong, Y., Martella, G., Tscherter, A., Martins, A., Bernardi, G., Roth, B.L., Pothos, E.N., Calabresi, P. and Shen, J. (2005) Nigrostriatal dopaminergic deficits and hypokinesia caused by inactivation of the familial Parkinsonism-linked gene DJ-1. Neuron, 45, 489-496. doi:10.1016/j.neuron.2005.01.041

[148] Gautier, C.A., Kitada, T. and Shen, J. (2008) Loss of PINK1 causes mitochondrial functional defects and increased sensitivity to oxidative stress. Proceedings of the National Academy Science USA, 105, 11364-11369. doi:10.1073/pnas.0802076105

[149] Healy, D.G., et al. and International LRRK2 Consortium (2008) Phenotype, genotype, and worldwide genetic penetrance of LRRK2-associated Parkinson's disease: A casecontrol study. The Lancet Neurology, 7, 583-590. doi:10.1016/S1474-4422(08)70117-0

[150] Lin, X., et al. (2009) Leucine-rich repeat kinase 2 regulates the progression of neuropathology induced by Parkinson's-disease-related mutant alpha-synuclein. Neuron, 64, 807-827. doi:10.1016/j.neuron.2009.11.006

[151] Li, Y., et al. (2009) Mutant LRRK2(R1441G) BAC transgenic mice recapitulate cardinal features of Parkinson's disease. Nature Neuroscience, 12, 826-828. doi: 10.1038/nn.2349

[152] Simon-Sanchez, J., et al. (2009) Genome-wide association study reveals genetic risk underlying Parkinson's disease. Nature Genetics, 41, 1308-1312. doi:10.1038/ng.487

[153] Venderova, K., et al. (2009) Leucine-Rich Repeat Kinase 2 interacts with Parkin, DJ-1 and PINK-1 in a Drosophila melanogaster model of Parkinson's disease. Human Molecular Genetics, 18, 4390-4404. doi:10.1093/hmg/ddp394

[154] Natale, G., Kastsiushenka, O., Fulceri, F., Ruggieri, S., Paparelli, A. and Fornai, F. (2010) MPTP-induced Parkinsonism extends to a subclass of TH positive neurons in the gut. Brain Research, 1355, 195-206. doi:10.1016/j.brainres.2010.07.076

[155] Hamza, T.H., et al. (2010) Common genetic variation in the HLA region is associated with late-onset sporadic Parkinson's disease. Nature Genetics, 42, 781-785. doi:10.1038/ng.642

[156] Li, X., Patel, J.C., Wang, J., Avshalumov, M.V., Nicholson, C., Buxbaum, J.D., Elder, G.A., Rice, M.E. and Yue, Z. (2010) Enhanced striatal dopamine transmission and motor performance with LRRK2 overexpression in mice is eliminated by familial Parkinson's disease mutation G2019S. Journal of Neuroscience, 30, 1788-1797. doi:10.1523/JNEUROSCI.5604-09.2010

[157] Im, S.A., Choi, H.S., Hwang, B.Y., Lee, M.K. and Lee, C.K. (2009) Augmentation of immune responses by oral administration of Gynostemma pentaphyllum ethanol extract. Korean Journal of Pharmacognosy, 40, 35-40.

[158] Choi, H.S., Park, M.S., Kim, S.H., Hwang, B.Y., Lee, C.K. and Lee, M.K. (2010) Neuroprotective effects of herbal ethanol extracts from Gynostemma pentaphyllum 
in the 6-hydroxydopamine-lesioned rat model of Parkinson's disease. Molecules, 15, 2814-2824.

doi:10.3390/molecules 15042814

[159] Sinicropi, M.S., Leone, F., Rovito, N. and Genchi, G. (2010) Behaviour of acetyl-L-carnitine injections (Nicetile $^{\mathbb{B}}$ fiale) with different drugs used for combined therapy. Advances in Therapy, 27, 547-554. doi:10.1007/s12325-010-0055-0

[160] Zhang, H.Y., Jia, H.Q., Liu, J.H., Ao, N., Yan, B., Shen, W.L., Wang, X.M., Li, X., Luo, C. and Liu, J.K. (2010) Combined R-alpha-lipoic acid and acetyl-L-carnitine exerts efficient preventative effects in a cellular model of Parkinson's disease. Journal of Cellular and Molecular Medicine, 14, 215-225. doi:10.1111/j.1582-4934.2008.00390.x

[161] Massart, R., Guilloux, J. P., Mignon, V., Sokoloff, P. and Diaz, J. (2009) Striatal Gpr88 expression is confined to the whole projection neuron population and is regulated by dopaminergic and glutamatergic afferents. European Journal of Neuroscience, 30, 397-414. doi:10.1111/j.1460-9568.2009.06842.x

[162] Jimenez-Del-Rio, M. and Velez-Pardo, C. (2006) Insulinlike growth factor-1 prevents $A \beta[25-35] /\left(\mathrm{H}_{2} \mathrm{O}_{2}\right)$-induced apoptosis in lymphocytes by reciprocal NF- $\mathrm{\kappa B}$ activation and p53 inhibition via PI3K-dependent pathway. Growth Factors, 24, 67-78. doi:10.1080/08977190500361788

[163] Jimenez-Del-Rio, M., Daza-Restrepo, A. and Velez-Pardo, C. (2008) The cannabinoid CP55, 940 prolongs survival and improves locomotor activity in Drosophila melanogaster against paraquat: Implications in Parkinson's disease. Neuroscience Research, 61, 404-411. doi:10.1016/j.neures.2008.04.011

[164] Avila-Gomez, I.C., Velez-Pardo, C. and Jimenez-Del-Rio, M. (2010) Effects of insulin-like growth factor-1 on rotenone-induced apoptosis in lymphocyte cells. Basic \& Clinical Pharmacology \& Toxicology, 106, 53-61.

[165] Velez-Pardo, C., Jimenez-Del-Rio, M., Lores-Arnaiz, S. and Bustamante, J. (2010) Protective effects of the synthetic cannabinoids CP55,940 and JWH-015 on rat brain mitochondria upon paraquat exposure. Neurochemical Research, 35, 1323-1332. doi:10.1007/s11064-010-0188-1

[166] Long-Smith, C.M., Sullivan, A.M. and Nolan, Y.M. (2009) The influence of microglia on the pathogenesis of Parkinson's disease. Progress in Neurobiology, 89, 277-287. doi:10.1016/j.pneurobio.2009.08.001

[167] Long-Smith, C.M., Collins, L., Toulouse, A., Sullivan, A.M. and Nolan, Y.M. (2010) Interleukin-1beta contributes to dopaminergic neuronal death induced by lipopolysaccharide-stimulated rat glia in vitro. Journal of Neuroimmunology, 226, 20-26. doi:10.1016/j.jneuroim.2010.05.030

[168] Antonelli, T., Tomasini, M.C., Fuxe, K., Agnati, L.F., Tanganelli, S. and Ferraro, L. (2007) Receptor-receptor interactions as studied with microdialysis. Focus on NTR/ D2 interactions in the basal ganglia. Journal of Neural Transmission, 114, 105-113. doi:10.1007/s00702-006-0558-7
[169] Ferraro, L., Tomasini, M.C., Beggiato, S., Guerrini, R., Salvadori, S., Fuxe, K., Calzà, L., Tanganelli, S. and Antonelli, T. (2009) Emerging evidence for neurotensin receptor 1 antagonists as novel pharmaceutics in neurodegenerative disorders. Mini Reviews in Medical Chemistry, 9, 1429-1438. doi:10.2174/138955709789957495

[170] Niknejad, H., Peirovi, H., Jorjani, M., Ahmadiani, A., Ghanavi, J. and Seifalian, A.M. (2008) Properties of the amniotic membrane for potential use in tissue engineering. European Cells and Materials, 15, 88-99.

[171] Niknejad, H., Peirovi, H., Ahmadiani, A., Ghanavi, J. and Jorjani, M. (2010) Differentiation factors that influence neuronal markers expression in vitro from human amniotic epithelial cells. European Cells and Materials, 19, 22-29.

[172] Bartels, A.L., Willemsen, A.T., Kortekaas, R., de Jong, B.M., de Vries, R., de Klerk, O., van Oostrom, J.C., Portman, A. And Leenders, K.L. (2008) Decreased bloodbrain barrier P-glycoprotein function in the progression of Parkinson's disease, PSP and MSA. Journal of Neural Transmission, 115, 1001-1009.

doi:10.1007/s00702-008-0030-y

[173] Thornton, E., Tran, T.T. and Vink, R. (2010) A substance $\mathrm{P}$ mediated pathway contributes to 6-hydroxydopamine induced cell death. Neuroscience Letters, 481, 64-67. doi:10.1016/j.neulet.2010.06.057

[174] Alachkar, A., Brotchie, J.M. and Jones, O. (2006) Alpha2-adrenoceptor-mediated modulation of the release of GABA and noradrenaline in the rat substantia nigra pars reticulata. Neuroscience Letters, 395, 138-142. doi:10.1016/j.neulet.2005.10.069

[175] Alachkar, A., Brotchie, J.M. and Jones, O. (2010) Binding of dopamine and 3-methoxytyramine as 1-DOPA metabolites to human alpha(2)-adrenergic and dopaminergic receptors. Neuroscience Research, 67, 245-249. doi:10.1016/i.neures.2010.03.008

[176] Alachkar, A., Brotchie, J.M. and Jones, O. (2010) Locomotor response to L-DOPA in reserpine treated rats following central inhibition of aromatic L-amino acid decarboxylase: Further evidence for non-dopaminergic actions of L-DOPA and its metabolites. Neuroscience Research, 68, 44-50. doi:10.1016/j.neures.2010.06.003

[177] Takasaki, S. (2009) Mitochondrial haplogroups associated with Japanese centenarians, Alzheimer's patients, Parkinson's patients, type 2 diabetic patients and healthy non-obese young males. Journal of Genetics and Genomics, 36, 425-434. doi:10.1016/S1673-8527(08)60132-0

[178] Suzuki, M., Kurita, A. and Hashimoto, M. (2006) Impaired myocardial 123Imetaiodobenzylguanidine uptake in Lewy body disease: Comparison between dementia with Lewy bodies and Parkinson's Disease. Journal of the Neurological Sciences, 240, 15-19. doi:10.1016/j.jns.2005.08.011

[179] Suzuki, M., Urashima, M. and Oka., H. (2007) Cardiac sympathetic denervation in bradykinesia-dominant Parkinson's disease. Neuroreport, 18, 1867-1870. doi:10.1097/WNR.0b013e3282f1ab33 